\title{
Variables demográficas en una provincia española: El caso de Soria
}

\author{
M. ${ }^{a}$ Teresa Rubio Benito *
}

\section{INTRODUCCIÓN}

Hay una relación entre el factor hombre y el factor geográfico, que dan lugar a la creación de una estructura económico-social, de la que el hombre como principal protagonista forma parte, considerándose el conjunto como algo orgánico, vivo y mutable.

Soria es el caso típico de provincia con población minimizada, compuesta por un número considerable de pequeños núcleos rurales distribuidos de forma bastante uniforme por todo el espacio provincial.

Distinguimos como uno de los rasgos fundamentales, la elevada altitud media, consecuencia no sólo de la zona afectada por el Sistema Ibérico, sino del conjunto provincial, con altitud superior a los $1.000 \mathrm{me}-$ tros en la mayor parte de su territorio. Incluso el Duero, eje de la provincia donde se asientan las principales villas, discurre a una altitud superior a los 800-900 metros. Este medio físico condiciona decisivamente el poblamiento; la tónica general hace pensar en un nivel de vida y desarrollo económico bajo, todavía no superado ya que tratándose de una provincia con economía eminentemente agrícola, los núcleos de población más importantes pueden señalarse en la ribera del rio Duero, zona llana, bien regada, de clima más suave que el resto de la provincia y de fácil acceso

\footnotetext{
* Departamento de Geografía. UNED.
} 
por la importancia de las comunicaciones, ya que atraviesa en este tramo la carretera principal.

La población se encuentra con mayor intensidad en el NE: La Sierra, Tierra de S. Pedro Manrique, dominio de los pequeños núcleos rurales. En el $W$ la concentración es menor, ya que coincide con las zonas húmedas de pinares comunitarios en núcleos aislados de población. En general la disposición es bastante rara en la provincia. Sólo en torno a Soria, Almazán, Burgo de Osma y en menor escala, a orillas del Duero y Jalón, encontramos granjas o alquerías en número escaso.

En el conjunto provincial puede decirse que la emigración es ya un hecho a finales del siglo XIx. La dinámica de la provincia se ve afectada por este movimiento que contribuye al estancamiento de los pueblos. El siglo XIX marca el comienzo de un proceso de crisis en los medios rurales, que seguimos arrastrando en nuestros dias. Las formas económico sociales que habian tenido vigencia a lo largo de muchas centurias, se presentan como no válidas. Se trata pues de un problema histórico que ha venido gestándose lentamente, y cuyas consecuencias se desencadenan a ritmo acelerado a partir del siglo XIX agudizándose de forma alarmante en la segunda mitad del siglo $x x$.

Una economía como la de Soria, cuya población tradicionalmente estaba adscrita al sector primario, tenía que acusar en su evolución un marcado retraso con respecto a otras zonas donde su desarrollo aunque lento, era evidente en los sectores secundario y terciario. En teoría, y a corto plazo, podía establecerse un mejor equilibrio entre los beneficios obtenidos y el número de habitantes, ya que al mantenerse estacionaria la renta, el reparto entre menor número de población, sería mayor.

Ahora bien, teniendo en cuenta que los emigrantes son gente joven en su mayoría, gente con iniciativa, su marcha aumentaba el desequilibrio entre población activa y población dependiente, que a largo plazo traeria graves consecuencias.

\section{EVOLUCIÓN DE LA POBLACIÓN}

Como puede apreciarse en el cuadro adjunto, la evolución de la población en Soria no sigue una tendencia sostenida a lo largo del siglo, sino que pueden marcarse claramente dos periodos: el primero, abarca 
la primera mitad del siglo, registrándose un crecimiento lento debido no sólo al débil crecimiento natural, sino también al proceso migratorio interior y continental iniciado entonces.

El segundo período, se inicia a mediados de siglo y continúa en la actualidad. Las tasas negativas arrojan una pérdida notable de población que hace pensar en la aceleración del movimiento migratorio y el de trasvase medio rural-urbano.

\begin{tabular}{lrr}
\hline ANOS & $\begin{array}{c}\text { TOTAL NAL. } \\
\text { HABITANTES }\end{array}$ & $\begin{array}{c}\text { PROV } \\
\text { SORIA }\end{array}$ \\
\hline & & \\
1900 & 18.594 .405 & 150.462 \\
1910 & 19.927 .150 & 156.354 \\
1920 & 21.303 .162 & 151.595 \\
1930 & 23.563 .867 & 156.207 \\
1940 & 25.877 .971 & 159.824 \\
1950 & 27.976 .755 & 161.182 \\
1960 & 30.430 .698 & 147.052 \\
1970 & 33.823 .918 & 114.956 \\
1981 & 37.616 .947 & 90.803 \\
& & \\
\hline
\end{tabular}

Fuente: Instituto Nacional de Estadística.

Toda la provincia puede considerarse como foco de emigración general cuya raiz hay que buscarla en la infraestructura económica con base en una agricultura pobre de secano, cerealista en su mayor parte, de explotación arcaica, poco evolucionada, y carente de industrias de transformación.

Un sector secundario con predominio de la empresa minúscula, la mayoría de las veces artesanal, que podia englobarse por su escasa importancia con el sector terciario poco significativo cuantitativamente, ya que sólo se reduciría a la capital.

Para analizar cuantitativamente el saldo migratorio global del conjunto provincial, emplearemos un método indirecto. Partiendo de los datos de población de hecho, que arrojan los censos y del crecimiento vegetativo en los periodos intercensales, calculamos la población teórica que 
corresponderia en caso de saldo migratorio nulo. La desviación de esta población teórica respecto a la que realmente existe, equivale al saldo migratorio en cada periodo intercensal.

\begin{tabular}{ccccc}
\hline AÑO & $\begin{array}{c}\text { POBLACION } \\
\text { DE HECHO }\end{array}$ & $\begin{array}{c}\text { CRECIMIENTO } \\
\text { VEGETATIVO }\end{array}$ & $\begin{array}{c}\text { POBLACIÓN } \\
\text { TEORICA }\end{array}$ & $\begin{array}{c}\text { SALDO } \\
\text { MIGRATORIO }\end{array}$ \\
\hline 1900 & 150.462 & - & - & - \\
1910 & 156.354 & 17.442 & 167.904 & 11.550 \\
1920 & 151.595 & 11.880 & 168.234 & 16.639 \\
1930 & 156.207 & 17.368 & 168.963 & 12.756 \\
1940 & 159.824 & 14.725 & 170.932 & 11.108 \\
1950 & 161.181 & 15.698 & 175.522 & 14.340 \\
1960 & 147.052 & 12.608 & 173.736 & 26.684 \\
1970 & 114.956 & 6.207 & 153.259 & 38.303 \\
1981 & 100.719 & 1.200 & 141.963 & 41.244 \\
\hline
\end{tabular}

Fuente: INE y elaboración propia.

Según los resultados expuestos en el esquema anterior, el crecimiento vegetativo de la población soriana ha sufrido un paulatino descenso desde 1940 con una débil recuperación en los dos lustros siguientes a la guerra civil.

A partir de 1950, este descenso se acelera hasta el momento actual en que el crecimiento vegetativo, se ha visto reducido a la tercera parte del de principios de siglo; con esto advertimos que se trata de una población vieja, que debe su envejecimiento al fuerte saldo migratorio intensificado precisamente en los años sesenta coincidiendo con el descenso en picado de la población de hecho y del crecimiento vegetativo.

Teniendo en cuenta que la densidad de población varía según sean óptimos o no el clima y el suelo, podemos afirmar que por regiones, las máximas densidades en todos los censos considerados, son las de la zona de Sierra, lindante a Picos de Urbión y al nacimiento del Duero, el Valle del Jalón, Campo de Gómara, Pinares y Tierra de Agreda, que sustentan mayor número de habitantes que la zona montañosa del norte. 
Variables demográficas en una provincia española: El caso de Soria

Para cada año censal, las densidades para la provincia han sido:

\begin{tabular}{ccl}
\hline ANOS & $\begin{array}{c}\text { DENSIDAD } \\
\text { PROVINCIAL } \\
\left(\mathrm{h} / \mathrm{km}^{2}\right)\end{array}$ & $\begin{array}{c}\text { DENSIDAD } \\
\text { NACIONAL } \\
\left(\mathrm{h} / \mathrm{km}^{2}\right)\end{array}$ \\
\hline & & \\
1900 & 14,5 & 36,84 \\
1910 & 15,1 & 39,48 \\
1920 & 14,6 & 42,21 \\
1930 & 15,1 & 46,69 \\
1940 & 15,4 & 51,27 \\
1950 & 15,6 & 55,43 \\
1960 & 14,2 & 60,29 \\
1965 & 12,4 & 63 \\
1970 & 11,1 & 67 \\
1981 & 9,8 & 74,66 \\
\hline
\end{tabular}

Fuente: INE y elaboración propia.

La densidad de España ha aumentado un $71 \%$ entre 1900 y 1965 , mientras la de Soria que se mantuvo en su debilidad casi invariable en 1930,1940 y 1950, descendió en 1960 y bruscamente en 1965 a 12,4 continuando esta marcha decadente en la actualidad.

I. DINAMISMO DEMOGRÁFICO

Natalidad: Antecedentes históricos

La evolución de la tasa de natalidad en España ha conservado valores altos, permaneciendo antes de 1900 superior a $35 \%$ si bien, en el transcurso de todos los años de esa época, experimentó pequeñas oscilaciones de ascenso y descenso, siempre por encima de dicha tasa. De 1878 a 1889, el año de máxima, lo marca 1881 con $37,1 \%$ bajando a $36 \%$ en los años sucesivos con ligeras variaciones que daban valores superiores a los mantenidos hasta 1878. 


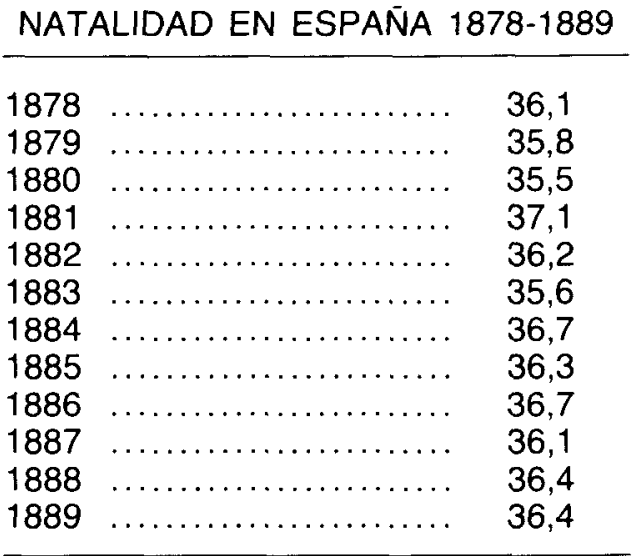

Fuente: INE.

La primera crisis demográfica de este siglo, vino marcada por la guerra colonial (1897-1902) iniciándose el lento descenso, acusado ya en 1900 en que la tasa de natalidad bajó a $33,8 \%$ ya que la posterior recuperación a partir de $1903(36,3 \%)$ no se mantuvo, descendiendo a $34,9 \%$ en 1905 , año en que realmente puede señalarse como punto de partida del descenso de la natalidad en el siglo xx. Ese descenso, con las características de leves variaciones y las grandes pérdidas en los períodos de crisis, colocó por vez primera en los años criticos de 1915 a 1920 (primera guerra mundial y pandemia gripal) y en el año 1939, el valor de la tasa por debajo de 30 y $20 \%$, pasando de la fase natal a la Denatal, siguiendo la nomenclatura del doctor A. Arbelo.

A partir de 1905, si bien conserva un índice alto, superior al $20 \%$ dentro siempre de la fase de "cultura", se observa un sensible descenso debido quizá a la tasa de mortalidad infantil más alta en la ciudad o a la emigración en principio más activa en la capital que en el campo. Este hecho tiene continuidad hasta 1945 en que observamos en todos los censos hasta 1970, un trasvase de la población del campo a la ciudad. Mientras la natalidad provincial decrece a pasos agigantados como ya hemos señalado anteriormente, los nacimientos aumentan en la ciudad casi al doble de la media nacional. La despoblación del campo es un hecho que contrasta con la jerarquización y aumento de servicios en las ciudades, y teniendo en cuenta que Soria capital es el único centro urbano de la provincia, la medida del aumento es casi infinita.

A partir de los años 50 los índices de natalidad no alcanzan para Soria, la media de España y siguen bajando de manera vertiginosa. El hecho de la regresividad de esta provincia encaja dentro del fenómeno general de la 

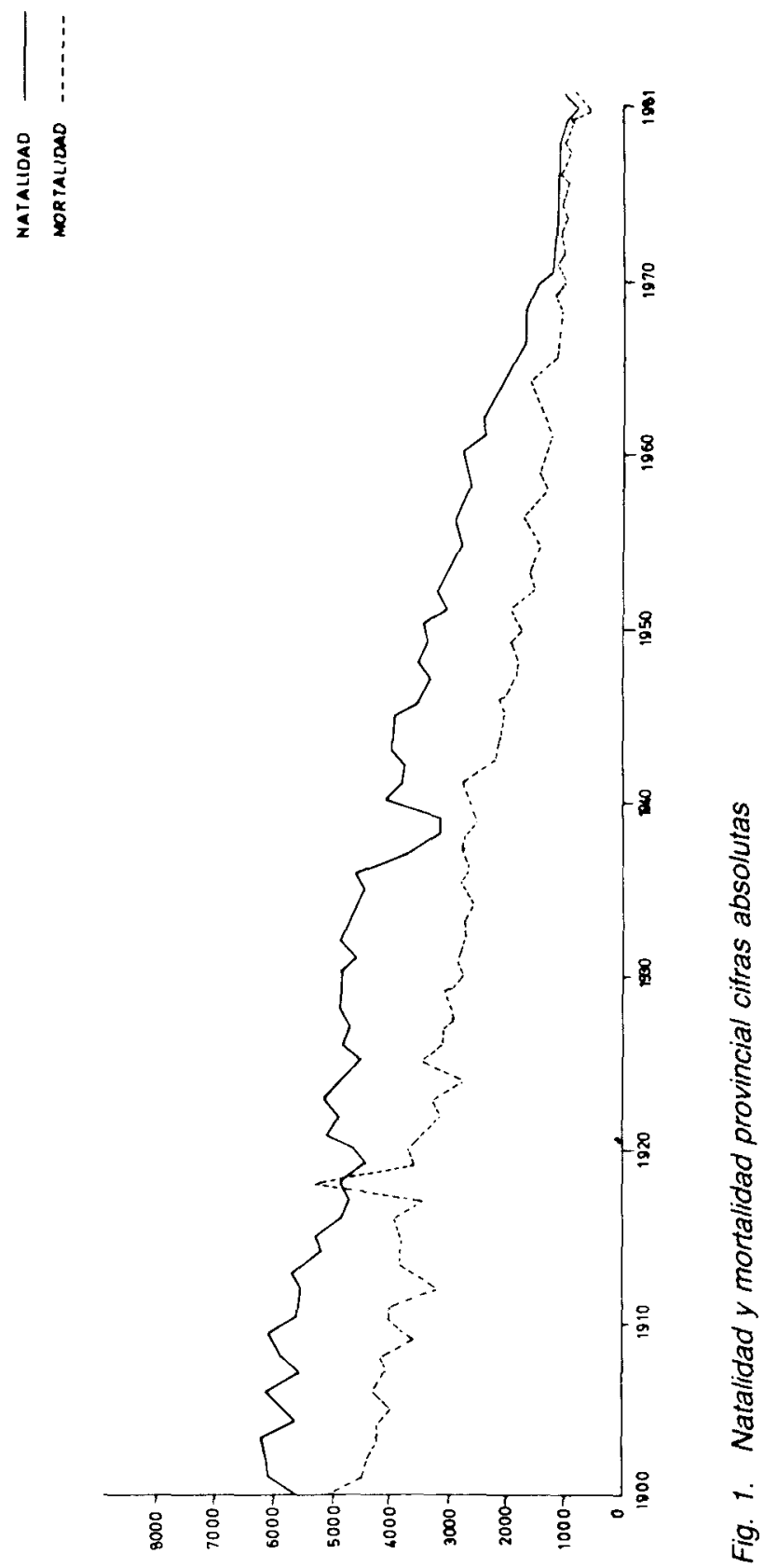
atracción que sobre la población ejercen los centros urbanos de cierta dimensión y las áreas industriales. En este sentido, las provincias menos densamente pobladas, son las que a corto plazo se despueblan a su vez más rápidamente. El descenso de natalidad es consecuencia del proceso migratorio desencadenado por una inadecuación de estructuras.

Los sectores industrial y de servicios no han podido retener una población de base eminentemente agrícola que el sector agrario infradesarrollado no ha podido soportar. Es gente joven la que emigra, con edades óptimas para la procreación. El proceso no se presenta de manera brusca; arranca de principios de siglo, siguiendo de forma más o menos continua, aunque la aceleración del mismo pertenezca a tiempos modernos.

NATALIDAD EN TANTO POR MIL

\begin{tabular}{cccc}
\hline & & & \\
AÑOS & ESPAÑA & SORIA PROVINCIA & SORIA CAPITAL \\
\hline 1900 & 33,8 & 37,66 & 36,80 \\
1905 & 34,9 & 39,72 & 29,23 \\
1910 & 32,6 & 38,05 & 29,41 \\
1915 & 30,7 & 33,14 & 25,15 \\
1920 & 29,3 & 26,64 & 24,19 \\
1925 & 28,9 & 29,27 & 30,20 \\
1930 & 28,2 & 31,01 & 35,33 \\
1935 & 25,7 & 28,35 & 23,72 \\
1940 & 24,3 & 25,27 & 22,43 \\
1945 & 22,8 & 24,39 & 27,03 \\
1950 & 20,0 & 20,58 & 26,65 \\
1955 & 19,8 & 17,37 & 24,12 \\
1960 & 21,6 & 18,10 & 31,65 \\
1961 & 21,1 & 16,29 & 31,71 \\
1962 & 21,0 & 16,23 & 35,42 \\
1963 & 21,3 & 15,51 & 35,92 \\
1964 & 21,9 & 14,88 & 32,25 \\
1965 & 21,1 & 13,69 & 34,10 \\
1966 & 20,76 & 13,70 & 36,19 \\
1967 & 20,91 & 13,90 & 34,64 \\
1968 & 20,22 & 12,47 & 35,49 \\
1969 & 20,00 & 12,94 & 39,15 \\
1970 & 19,50 & 11,74 & 33,66 \\
1981 & 14,13 & 10,39 & 30,70 \\
\hline
\end{tabular}

Fuente: INE y elaboración propia. 
Fase de cultura. Primer periodo

La fase natal o de "cultura", arroja fuertes tasas de natalidad, superiores a $29 \%$ habitantes. En cambio en la Denatal, las tasas se sitúan por debajo de $20 \%$ y los elementos materiales sustituyen los espirituales de la "cultura" por los artificiales de la "civilización".

El primer periodo de la fase de cultura es por entero favorable a la natalidad, con coeficientes superiores a $30 \%$ ayudados por una nupcialidad elevada, aunque en el caso de la provincia de Soria no alcance el $10 \%$ dato significativo teniendo en cuenta que la natalidad y mortalidad infantiles, superan la media nacional, con coeficientes superiores a $100 \mathrm{o}$ a 70 fallecidos menores de un año por mil nacidos vivos, según la vieja clasificación de Debré. Otro factor a considerar es la diferencia de signo dentro de la mortalidad infantil que arroja cifras más elevadas en el sector urbano que en el rural, manteniéndose una mortalidad general alta, con coeficientes cercanos a los de natalidad, sobre todo en la capital, de tal forma que el crecimiento vegetativo da saldos bajos, e incluso negativos en la capital.

Si revisamos las cifras relativas, nos damos cuenta fácilmente de que la pendiente iniciada en 1900 , es continua en todos los órdenes si bien podemos marcar unos jalones teóricos que nos faciliten su estudio.

La primera etapa podiamos señalarla de 1900 a 1905. La nupcialidad provincial oscila desde $9,96 \%$ en 1900 a $7,50 \%$ en 1910 . Los tres primeros años del siglo, mantienen el ritmo inicial, descendiendo a $8 \%$ con distintos valores de 1902 hasta 1909. En la capital las diferencias no son marcadas, alternando de 7 a $5 \%$.

La natalidad va a pasar de $37-39 \%$ en la provincia como cifras dominantes de 1900-1915 a $33 \%$ continuando el descenso, y en la capital de 36 a $25 \%$.

En cuanto a la mortalidad, muy semejante en la provincia y la capital, con mayor saldo en esta última, pasa de 33 a $25 \%$.

La segunda etapa a señalar es más bien un paréntesis, abierto con la guerra civil española y cerrado con el final de la guerra mundial que siguió a la nuestra, aun cuando las diferencias son más notables desde 1936 hasta 1939. 
M. ${ }^{a}$ TERESA RUBIO BENITO

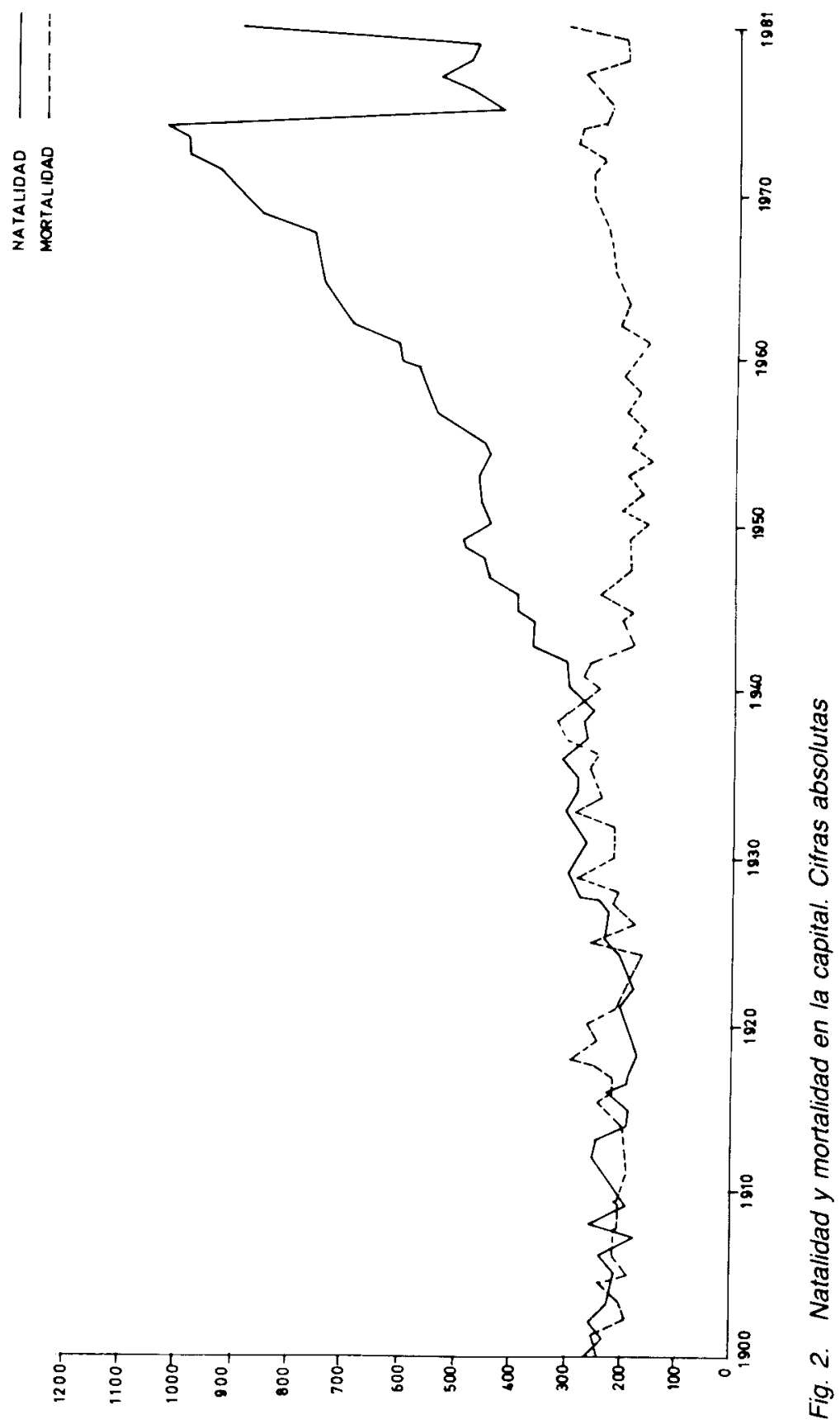




\section{NATALIDAD EN SORIA DURANTE LA GUERRA CIVIL ESPAÑOLA (\%)}

\begin{tabular}{lll}
\hline & & \\
ANNOS & PROVINCIA & CAPITAL \\
\hline & & \\
1936 & 28,94 & 25,36 \\
1937 & 23,14 & 21,52 \\
1938 & 19,58 & 21,24 \\
1939 & 19,31 & 20,65 \\
\hline
\end{tabular}

Fuente: INE y elaboración propia.

El descenso queda compensado en parte por la recuperación posterior y es en 1949 o mejor 1950, fecha más redondeada ya que viene marcada por el censo, donde realmente existe un escalón que marca la transición de la fase denatal a la fase de civilización, bajando la natalidad a menos de $20 \%$.

Las curvas de nupcialidad, natalidad y mortalidad en tanto por mil muestran en primer lugar, una natalidad mantenida en los diez primeros años, como hemos señalado anteriormente con un descenso que abarca de 1918 a 1920, coincidiendo el primer año con un aumento desmesurado de la mortalidad general debido a la famosa epidemia gripal del año 1918 que asoló la Península.

Otro bache profundo en la curva de la natalidad que se corresponde con el mayor señalado en la nupcialidad, viene marcado en el año 1936 bache que tras una efímera recuperación, se agudiza como hemos dicho en 1950 y cae en picado a partir del 60 en cuanto a la natalidad se refiere, manteniéndose en tono equilibrado, sin altos ni bajos remarcables, la mortalidad y nupcialidad.

Si la provincia superaba hasta 1950 el indice medio de natalidad en España, bajando progresivamente a partir de esta fecha casi a la mitad de la media nacional, la capital ofrece un marcado contraste, ya que en ella se opera el fenómeno contrario.

Durante los cinco primeros años del siglo, Soria capital mantiene una natalidad por encima de $30 \%$, superior a la media nacional, aunque sin alcanzar nunca las elevadas cifras provinciales. 


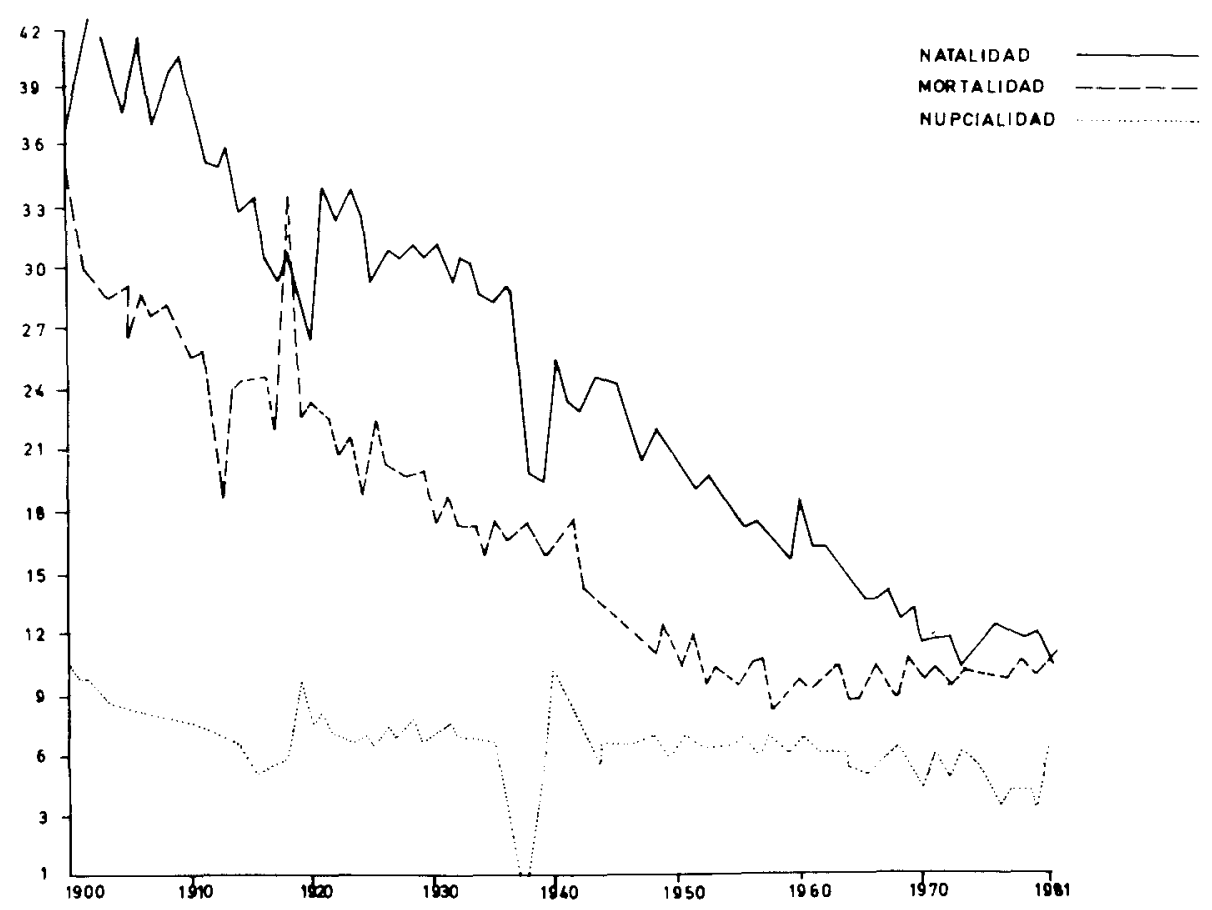

Fig. 3. Natalidad, mortalidad y nupcialidad provincia $0 \%$.

\section{NATALIDAD}

\begin{tabular}{lll}
\hline AÑO & PROVINCIA & CAPITAL \\
\hline & & \\
1900 & 37,66 & 36,80 \\
1901 & 40,59 & 31,88 \\
1902 & 40,20 & 35,76 \\
1903 & 40,58 & 32,84 \\
1904 & 37,42 & 32,34 \\
\hline
\end{tabular}

Fuente: INE y elaboración propia. 
En este primer período de la fase de cultura que hemos analizado, la tasa de natalidad y la de mortalidad infantil son totalmente independientes y están libres de relación de causalidad. Son, como dijo Villar Salinas, "dos epifenómenos de causa común".

El crecimiento de la población se hace casi exclusivamente a expensas de los natalicios, ya que en esta fase no existe neomalthusianismo. Las crisis demográficas denatales se acompañan de un descenso paralelo del coeficiente de nupcialidad y son siempre transitorias, la compensación posterior es rápida aunque no siempre eficaz, al menos en esta provincia en que la tónica general de despoblación se impone a cualquier otra.

Fase de cultura. Segundo periodo

El segundo período de esta fase de cultura es de transición a la fase de civilización. Comienza en Europa en 1886 y en España en 1926. Teniendo en cuenta que la entrada de un país en este segundo período de la "fase de cultura", coincide con el fenómeno de "cambio de signo" de su mortalidad infantil, vamos a estudiar aqui este factor aun cuando ambas tasas sean independientes y tratemos la mortalidad general más tarde, considerando que la evolución de los dos fenómenos, es prácticamente paralela.

En la estimación de la mortalidad infantil se presentan algunas dificultades ante la imprecisión de las estadisticas en la distribución entre nacidos muertos y fallecidos al nacer.

No se incluyen en la cifra de nacidos a los niños que no sobreviven veinticuatro horas al parto, considerándolos como abortos.

La mortalidad infantil será pues el porcentaje de fallecidos durante el primer año de vida en relación al total de nacidos sobrevivientes a las veinticuatro horas.

Las cifras absolutas nos dan cuenta de una mortalidad infantil elevada. En 1900, 1.316 niños muertos en la provincia, cifra record del siglo, y 46 en la capital, cuando en España la cifra era de 128.263, quince años más tarde, la tasa habia descendido, aunque seguia sobrepasando la media nacional.

El censo de 1917, arroja en números brutos la cifra de 750 para la provincia y 34 para la capital, lo que supone el 21,68\% de defunciones 
en el primer caso y el $15,60 \%$ en el segundo, cuando el tanto por ciento de España estaba en 20,06.

Si bien los progresos alcanzados en la medicina e higiene hacian suponer un descenso espectacular en las cifras de mortalidad infantil, continuaron las tasas elevadas por encima del $20 \%$ del total de defunciones en la provincia y del $15 \%$ en la capital, siendo en esta última 1921 , el año de máxima mortalidad del siglo con 57 defunciones en números brutos $(25,68 \%$ defunciones), de 204 nacidos vivos.

En los años de la guerra civil el descenso de mortalidad infantil va ligado a la escasez de nacimientos.

\section{MORTALIDAD EN SORIA DURANTE LA GUERRA CIVIL ESPAÑOLA (tantos por \%o)}

\begin{tabular}{|c|c|c|c|c|c|c|}
\hline \multirow{2}{*}{ AÑOS } & \multicolumn{2}{|c|}{ NACIDOS VIVOS } & \multicolumn{2}{|c|}{$\begin{array}{l}\text { NIÑOS MUERTOS } \\
(<1 \text { AÑO) }\end{array}$} & \multicolumn{2}{|c|}{ NIÑOS MUERTOS $(\% \circ)$} \\
\hline & PROV. & CAPITAL & PROV. & CAPITAL & PROV. & CAPITAL \\
\hline 1936 & 4.596 & 301 & 526 & 22 & 19,72 & 8,59 \\
\hline 1937 & 3.687 & 273 & 520 & 49 & 18,86 & 16,28 \\
\hline 1938 & 3.129 & 272 & 414 & 55 & 14,88 & 17,24 \\
\hline 1939 & 3.094 & 265 & 353 & 35 & 14,09 & 11,99 \\
\hline
\end{tabular}

Fuente: I.N.E. y elaboración propia.

Los censos de 1950 y 1960 suponen dos topes que marcan el descenso de las doscientas por 100 defunciones a las 100 en el primera y por debajo de 100 en el segundo, en cuanto a las cifras provinciales se refiere. Es precisamente en estos años 50 donde se aprecia la encrucijada del cambio de signo de la mortalidad infantil, cambio que experimentó España en 1926, ya que a partir de este año, la tasa de mortalidad infantil urbana es siempre inferior a la del medio rural. 
Variables demográficas en una provincia española: El caso de Soria

\begin{tabular}{|c|c|c|c|c|c|c|}
\hline \multirow{2}{*}{ AÑOS } & \multicolumn{2}{|c|}{ NACIDOS VIVOS } & \multicolumn{2}{|c|}{$\begin{array}{l}\text { NIÑOS MUERTOS } \\
\qquad<1 \text { ANNO })\end{array}$} & \multicolumn{2}{|c|}{ NIÑOS MUERTOS (\%) } \\
\hline & PROV. & CAPITAL & PROV. & CAPITAL & PROV. & CAPITAL \\
\hline 1950 & 3.361 & 444 & 191 & 8 & 10,99 & 4,60 \\
\hline 1951 & 3.065 & 451 & 208 & 17 & 10,66 & 7,87 \\
\hline 1952 & 3.196 & 462 & 171 & 15 & 10,90 & 7,65 \\
\hline 1953 & 3.059 & 462 & 141 & 14 & 8,42 & 6,79 \\
\hline 1954 & 2.915 & 445 & 149 & 11 & 10,07 & 7,05 \\
\hline 1955 & 2.810 & 457 & 143 & 12 & 9,52 & 6,28 \\
\hline 1956 & 2.847 & 523 & 156 & 11 & 9,15 & 6,32 \\
\hline 1957 & 2.772 & 555 & 147 & 17 & 8,55 & 8,55 \\
\hline 1958 & 2.659 & 555 & 113 & 15 & 8,30 & 8,43 \\
\hline 1959 & 2.645 & 569 & 104 & 13 & 7,14 & 6,34 \\
\hline 1960 & 2.721 & 607 & 85 & 13 & 6,12 & 6,63 \\
\hline 1961 & 2.463 & 616 & 76 & 10 & 5,74 & 5,96 \\
\hline
\end{tabular}

Fuente: INE y elaboración propia.

Y para complementar estos datos, vamos a relacionarlos con la evolución nacional: 
EVOLUCIÓN DE LA MORTALIDAD INFANTIL (\% de defunciones de menores de 1 año sobre total de nacidos vivos)

\begin{tabular}{cccc}
\hline & & & \\
ANNOS & ESPANA & PROVINCIA & CAPITAL \\
\hline & & & \\
1901 & 18,5 & - & - \\
1905 & 16,1 & 24,0 & 22,8 \\
1910 & 14,9 & 23,9 & 22,6 \\
1915 & 15,2 & 23,0 & 20,3 \\
1920 & 16,5 & 22,62 & 19,77 \\
1925 & 13,6 & 21,14 & 15,95 \\
1930 & 11,7 & 21,17 & 13,00 \\
1931 & 11,6 & 22,03 & 17,70 \\
1932 & 11,2 & 21,32 & 16,96 \\
1933 & 11,2 & 21,29 & 15,31 \\
1934 & 11,3 & 20,06 & 15,29 \\
1935 & 10,9 & 22,13 & 13,55 \\
1940 & 10,8 & 16,64 & 17,74 \\
1945 & 8,5 & 19,09 & 17,01 \\
1950 & 6,4 & 10,99 & 4,60 \\
1955 & 5,1 & 9,52 & 6,28 \\
1960 & 3,5 & 6,12 & 6,63 \\
1965 & 2,9 & 4,32 & 7,94 \\
1966 & 2,8 & 4,60 & 2,51 \\
1967 & 2,6 & 4,48 & 7,23 \\
1968 & 2,4 & 2,81 & 3,81 \\
1969 & 2,2 & 2,54 & 4,47 \\
1970 & 2,07 & 2,31 & 3,83 \\
& & & \\
\hline
\end{tabular}

Fuente: INE y elaboración propia.

A la vista de todos los datos expuestos hasta el momento, podemos decir que una vez alcanzada la fase de civilización caracterizada demográficamente por una natalidad y mortalidad infantil débiles (inferiores al $20 \%$ ) las cifras absolutas y relativas de nupcialidad, natalidad y mortalidad general, nos señalan como el crecimiento natural de la población ha venido haciéndose cada vez más a expensas de la disminución progresiva de la cifra de fallecidos, ya que la cifra de matrimonios se sostiene y la de natalicios tiende a disminuir a la par que la mortalidad en el primer año de vida. 
En efecto, las instalaciones sanitarias adecuadas desde fines del decenio de 1911-20, sobre todo en las capitales al crearse en 1932 un centro de Higiene infantil en cada capital de provincia, la mayor asistencia médica en los medios rurales, la labor de divulgación e higiene iniciada en los años 41-50, la fundación de los centros maternales y pediátricos de urgencia, la facilidad de transporte y medios de comunicación en los centros urbanos, han mermado de forma notable las bajas en los primeros años de vida paliando asi la debilidad de un saldo vital que acosa el envejecimiento de la población; envejecimiento por otra parte, extendido por casi toda Europa aunque se deba a control de natalidad, y no a emigración como en el caso de Soria.

Dentro de la linea europea aunque de forma menos acusada, entra la natalidad nacional. Así, la evolución demográfica de estos 30 años últimos, excepto el periodo de guerra civil (1936-39), muestran como el proceso civilizador ha disminuido la natalidad española. En la época actual, la mayoria de las naciones se encuentran en la fase de civilización más o menos evolucionada, según su época de entrada en esta fase. En general, el fenómeno va unido a la distribución de la civilización que sigue la marcha NW a SE en Europa y NE a SW en España.

En Europa la pionera de este movimiento ha sido siempre Francia, que entra en la "fase de civilización" en 1906, con un coeficiente de 19,9. Le siguen los países nórdicos, los centroeuropeos y los del Este tras la Segunda Guerra Mundial y los años de postguerra, de tal forma que en 1961, casi todas las naciones europeas han alcanzado la «fase de civilización" excepto ocho países entre ellos España.

En nuestro país el núcleo catalán fue el pionero, concretamente Tarragona, es la primera provincia que en 1926 baja su natalidad por debajo de $20 \%$. En cuanto a las capitales, Lérida va a la cabeza. La explicación al hecho de que este paso lo dieran provincias conservadoras y profundamente religiosas como Tarragona y Lérida, puede encontrarse en la influencia de los trabajadores emigrados a Francia que volvian con conocimientos sobre el control de la natalidad. Salvo estas provincias de carácter esencialmente rural, la evolución siguió la línea de las zonas industrializadas, para terminar con las Islas Canarias y a mediados de siglo alcanzaban los coeficientes de natalidad más altos de Europa. Ya hemos señalado anteriormente la entrada de la provincia de Soria en esta última fase que podemos fijar en 1951, un año después de Galicia y 25 de conjunto nacional. 
Mortalidad: Antecedentes Históricos

El descenso de la mortalidad, sobre todo epidémica, es el factor que impulsa los primeros pasos del nuevo ciclo demográfico europeo que ya en el siglo XVIII se caracteriza por el progresivo aumento del número de hombres.

De acuerdo con NADAL, J. las etapas de este ciclo podrian escalonarse así:

1. Reducción de la mortalidad catastrófica (sobre todo epidémica) a partir del siglo xvill.

2. ${ }^{a}$ Reducción de la mortalidad ordinaria a partir de la $1 .^{a}$ mitad del siglo $x \mid X$.

3. ${ }^{a}$ Reducción de la fecundidad a partir de la $2 .^{a}$ mitad del siglo Xix.

La tercera y cuarta etapa, supondrían un envejecimiento notorio de la población desde comienzos del siglo $x x$, a la par que una desaceleración del crecimiento.

Las dos primeras etapas han permitido la tercera, y las restantes son consecuencia de las anteriores, es una cadena en la que cada eslabón sirve de apoyo al siguiente. Este es un fenómeno europeo, aunque la revolución demográfica y la entrada en un nuevo ciclo de población, son un fenómeno mundial en el que la variación de un pais a otro estriba en la cronologia. $Y$ es aqui precisamente donde hay que hacer hincapié para saber si la evolución española va a compás de la europea, y dentro de ella, qué papel desempeña la provincia de Soria.

Se ha escrito mucho sobre las epidemias que diezmaron la población en el mundo, durante la Edad Media y en siglos posteriores, relacionando estos sucesos con las épocas de hambre y escasez. Incluso se han hecho baremos entre la mortalidad y el precio del trigo, alimento básico en aquella época, demostrando hasta qué punto el hambre engrendraba, o mejor favorecía, todo tipo de epidemias. Lo cierto es que las principales vinieron a España a través del continente o de los puertos mediterráneos, y por ser la península el último reducto de Europa occidental, se extendieron con diez años de retraso con respecto al punto de partida.

\section{Mortalidad General}

Los gráficos provinciales de cifras absolutas nos muestran como la mortalidad ha seguido una línea descendente moderada desde principios 
de siglo, con las excepciones de 1916 por la epidemia gripal y 1925 , no apreciándose apenas los estragos de la guerra del 36, de tal forma que solo el descenso brusco en la curva de natalidad para esos mismos años nos revelan la excepcionalidad de la situación.

\section{DEFUNCIONES}

\begin{tabular}{lll}
\hline & & \\
AÑOS & PROVINCIA & CAPITAL \\
\hline & & \\
\hline 1930 & 2.759 & 223 \\
1931 & 2.864 & 226 \\
1932 & 2.730 & 230 \\
1933 & 2.739 & 294 \\
1934 & 2.573 & 242 \\
1935 & 2.775 & 251 \\
1936 & 2.667 & 256 \\
1937 & 12757 & 301 \\
1938 & 2.782 & 319 \\
1939 & 2.505 & 292 \\
1940 & 2.644 & 248 \\
\hline
\end{tabular}

Cifras absolutas

Fuente: INE y elaboración propia.

Quizá la explicación haya que buscarla como siempre en la despoblación general de Soria, ya que el censo inmediatamente anterior a la guerra el de 1930, arroja tan sólo 11.582 hombres para toda la provincia en la edad comprendida entre 21 y 30 años, ambos inclusive, y 8.163 entre los 31 y 40 , cifras bajisimas en comparación con otras provincias del Sistema Ibérico. Cuenca por ejemplo en las mismas edades daba 24.002 entre 21 y 30 años y 18.426 entre 31 y 40 años.

A partir de 1942, fecha importante como ya hemos dicho para el retroceso de la mortalidad infantil, por la puesta en marcha de las adecuadas instalaciones sanitarias, la gráfica de mortalidad sigue una suave linea descendente sin marcados altibajos, haciéndose estacionaria a partir de 1965 hasta la actualidad.

La gráfica de natalidad sigue asi mismo la tónica de descenso, sobre todo a partir de 1960 y 1965, acercándose peligrosamente a la línea de mortalidad y es de preveer si sigue este ritmo que la rebase pronto, dando el crecimiento vegetativo un saldo negativo. 


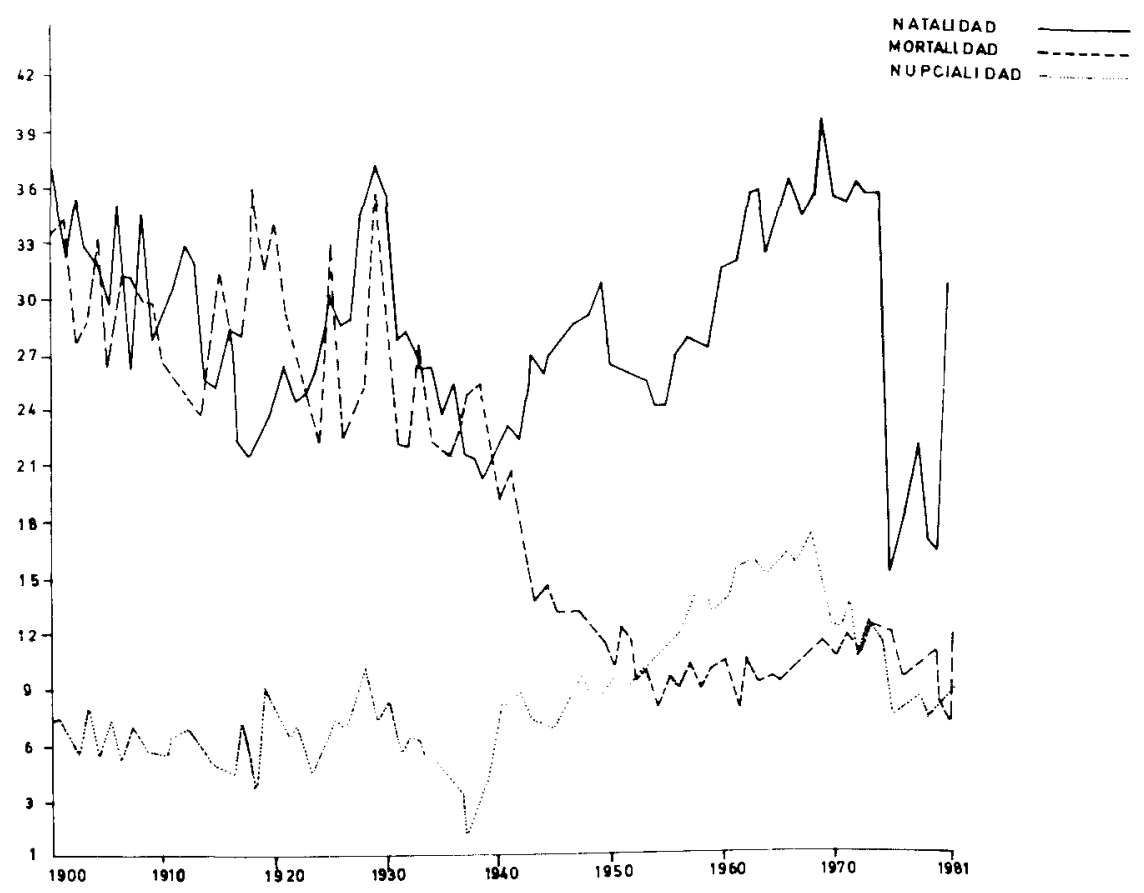

Fig. 4. Natalidad, mortalidad y nupcialidad capital

NATALIDAD Y MORTALIDAD PROVINC. POR 1000 HABITANTES

\begin{tabular}{|c|c|c|c|}
\hline AÑOS & NAT. PROV. & MORT. PROV. & CREC VEGET \\
\hline 1960 & 18,10 & 9,39 & 8,71 \\
\hline 1961 & 16,29 & 9,04 & 7,25 \\
\hline 1962 & 16,23 & 9,42 & 6,81 \\
\hline 1963 & 15,51 & 10,42 & 5,09 \\
\hline 1964 & 14,88 & 8,83 & 6,05 \\
\hline 1965 & 13,69 & 8,90 & 4,79 \\
\hline 1966 & 13,70 & 10,16 & 3,54 \\
\hline 1967 & 13,90 & 9,54 & 4,36 \\
\hline 1968 & 12,47 & 8,79 & 3,68 \\
\hline 1969 & 12,94 & 10,57 & 2,37 \\
\hline 1970 & 11,74 & 9,49 & 2,25 \\
\hline 1981 & 10,39 & 10,65 & $-0,26$ \\
\hline
\end{tabular}

Fuente: INE y elaboración propia. 
La capital ofrece un vivo contraste con la provincia, acusando su papel de tierra de promisión de la población rural. La despoblación del campo en favor de la capital, se pone una vez más de manifiesto, en la curva que expresa la natalidad, a partir de 1942 en una ascensión contínua casi vertical desde 1961, a la par que hay que tener en cuenta también las instalaciones del seguro de enfermedad de la Seguridad Social, que atienden en la ciudad la mayor parte de los alumbramientos de la provincia. El hecho es que las gráficas de natalidad y mortalidad que iban trenzadas desde principios de siglo con continuas interferencias, se separan a partir de 1940 acentuándose cada vez más la separación entre ambas líneas.

Hay que señalar nuevamente como hechos a destacar, la mortalidad extraordinaria de 1918 y la del 36, aunque en el primer caso no se puede señalar como única causa la epidemia de gripe del 18 , teniendo en cuenta que el crecimiento vegetativo de la capital arroja un saldo negativo que abarca de 1914 a 1922 ambos inclusive.

Efectivamente 1918 fue dentro de este período de baja, el que dio la máxima pérdida de población tanto en la provincia ( -412 crecimiento vegetativo) como en la capital ( -115 crecimiento vegetativo).

Los años de la guerra arrojan igualmente saldos negativos menores en proporción a los anteriores porque la natalidad es mayor. En el período comprendido entre 1922, último año de la crisis señalada y el comien$z 0$ de la guerra del 36, incluso hasta nuestros días, solo 1925 presenta pérdida de población en la capital 235 nacimientos y 257 defunciones dan un saldo negativo de 22 personas.

Nupcialidad: Introducción

El fomento y la protección del estado matrimonial constituyó una de las obsesiones de la literatura socioeconómica en el siglo xvill y parte del XIX por la importancia de su papel reproductor en el conjunto de la población, de tal forma que no sólo se alentaba al matrimonio en sí, sino a que las edades fueran óptimas para la fecundación.

NADAL, J., recoge en su obra los datos que J. W. Leasure da para las tasas de fecundidad en España a lo largo de medio siglo: 
TASAS DE FECUNDIDAD MATRIMONIAL EN ESPAÑA 1900-1950

\begin{tabular}{llllll}
\hline AÑOS & 1900 & 1910 & 1920 & 1930 & 1950 \\
\hline TASAS & 1,509 & 1,439 & 1,284 & 1,181 & 0,911 \\
\hline
\end{tabular}

La omisión de 1940, se debe a que su proximidad con la guerra civil no hacen fiables los datos que arroja.

Globalmente, de 1900 a 1950 , la tasa de fecundidad matrimonial española se redujo en un $40 \%$, reducción progresiva en el tiempo y en el espacio, aunque no uniforme por la distinta evolución que han seguido las provincias españolas en las etapas de cultura y civilización.

De hecho, es dificil precisar las causas que han motivado este descenso, y en todo caso no podríamos concretizarlas en una única tendencia; lo cierto es que el fenómeno es general en el mundo y ni España ni la provincia de Soria son excepciones en la regla.

\section{Nupcialidad: Provincia y Capital}

La evolución de la nupcialidad, independientemente de la fecundidad matrimonial, ha seguido en la provincia de Soria un curso alterado por los acontecimientos que han marcado todo el movimiento demográfico en general.

No obstante, vamos a detallar paso a paso las etapas seguidas en las gráficas de cifras absolutas a escala provincial y de la capital. Prácticamente, el descenso en la nupcialidad provincial se inicia con el siglo aunque sea el año 1902 el que marca la tónica a seguir a lo largo de la centuria con altibajos y recuperaciones correspondientes. Son precisamente estos baches y los períodos que median entre uno y otro los que vamos a considerar a la hora de marcar unas etapas concretas.

Si hasta 1913, desde 1900, se observa un lento descenso sin cambios bruscos, en la gráfica de la provincia, 1914, inicia el primer bache, acusado en los años siguientes, 1915 y 1916, como puntos más bajos y continúa en el 17 y 18 , año este último de la terrible pandemia gripal que afectó a toda la peninsula. 


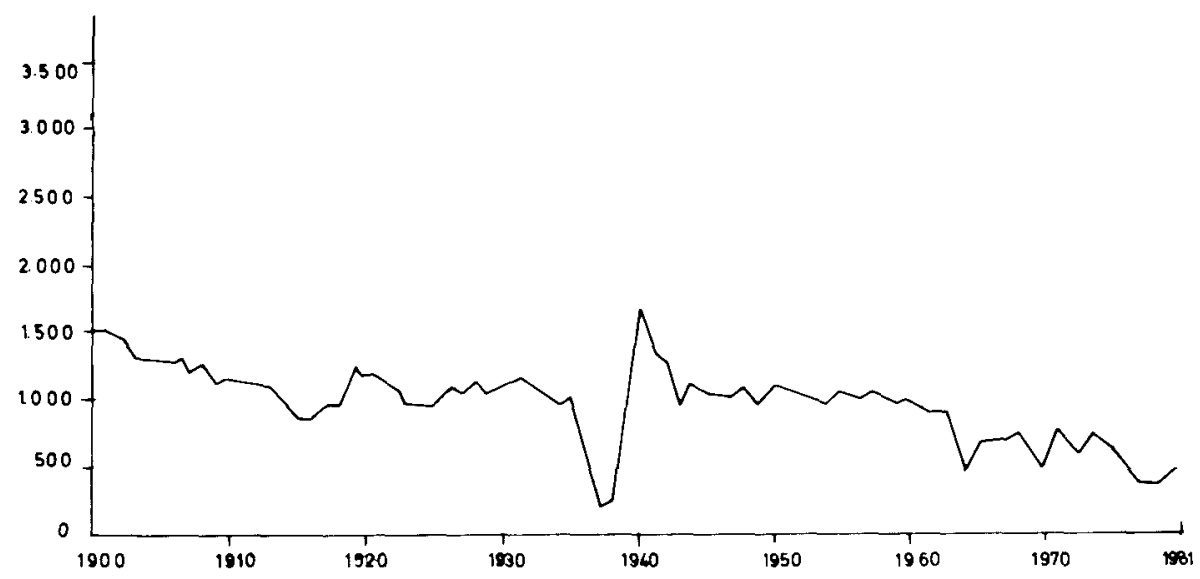

Fig. 5.1. Nupcialidad provincial, cifras absolutas

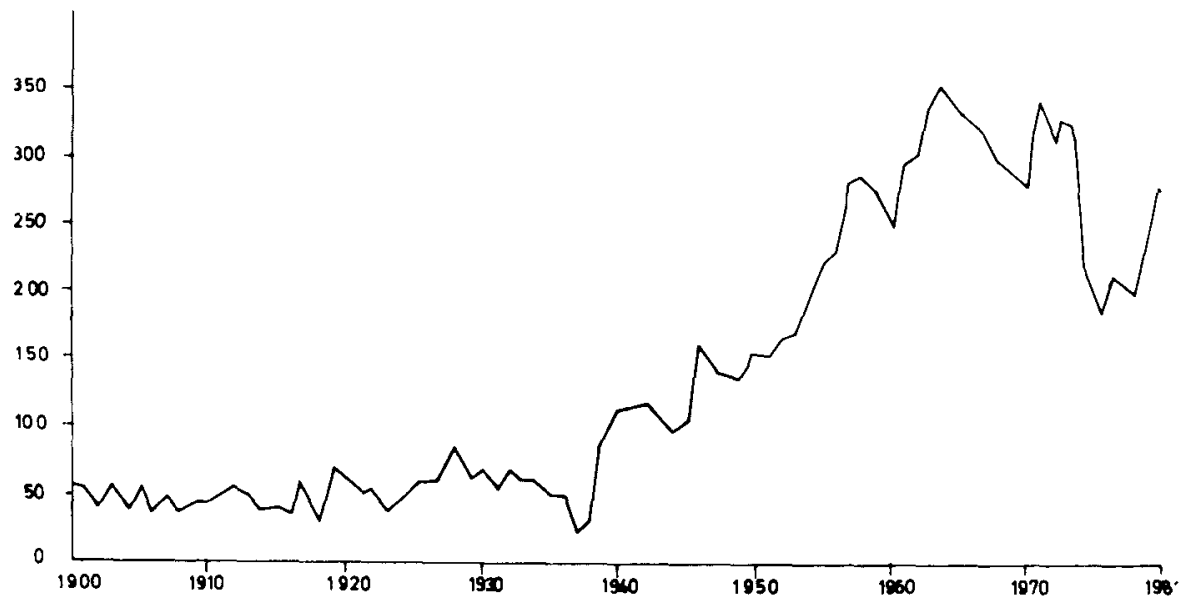

Fig. 5.2. Nupcialidad capital, cifras absolutas 
Efectivamente, la primera guerra mundial que estalló en 1914, marcó profundamente la trayectoria demográfica española, positivamente en las áreas industrializadas y negativamente en las zonas rurales. La neutralidad de España en el conflicto, fomentó el comercio, produciendo un aumento extraordinario de la demanda exterior tan favorable a los propietarios de los medios de producción, como perjudicial a los asalariados. "Una oleada de prosperidad invadió el país enriqueciendo a los particulares y al estado" '. Esta frase es muy significativa porque encierra la clave del problema que favoreció la agitación social. Era "fortuna de los particulares" pero no beneficio público, a pesar del aumento que experimentó el número de obreros empleados y por tanto, la capacidad de rendimiento en la industria. La escasez de alimentos repercutió en un alza formidable del coste de vida que la situación de los jornaleros especialmente precaria en el campo, no pudo soportar, viéndose obligados muchos de ellos a emigrar a las ciudades. La pérdida de población por esta causa, fue mucho mayor que la debida a la pandemia, condicionando de manera decisiva el movimiento natural, ya que la caída de la nupcialidad, frenó la natalidad descendiendo las cifras relativas en tantos por mil a $0,34,5,47,5,39,5,94$ y 5,85 para el período considerado (19141918), por debajo de la media nacional, que arrojaba en los mismos años las tasas siguientes: 6,54 (1914); 6,23 (1915); 6,59 (1916); 6,81 (1917); 6,72 (1918).

Los tres años siguientes son de recuperación, tan espectacular como breve, ya que si bien se alcanzó en 1919 el 9,90\%, superior al nivel estimado para el total nacional $(8,07)$, en años sucesivos se bajó al 7,72 , 7,81 y 7,24 que no se mantuvieron por mucho tiempo, iniciándose el descenso en 1922 hasta 1925.

No se trata en este caso de un descenso espectacular, ya que las fronteras entre este bache de nupcialidad y el período siguiente apenas son remarcables, manteniéndose de 1926 al 35 un tono más o menos equilibrado, alternando las tasas entre 6 y 7 por mil, semejante a la media nacional.

La inflexión de la curva en los años de la guerra, es el rasgo más acusado, el suceso más importante reflejado ya en las gráficas generales de natalidad, mortalidad y nupcialidad, inflexión que se corresponde con la de natalidad de los mismos años, por la íntima relación que tienen estos fenómenos. 1937 alcanza el vértice de esta curva negativa con un

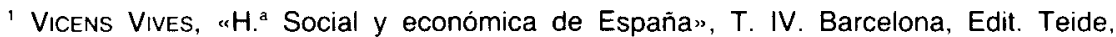
pág. 321. 
eje de los 1.000 en 1935 al de los 100 en tan sólo dos años de diferencia, baja que mantiene con un leve cambio en el año siguiente alcanzando 1,55, casi la cuarta parte del indice nacional para 1938.

\section{MATRIMONIOS EN SORIA EN AÑOS DE GUERRA}

\begin{tabular}{|c|c|c|c|c|c|c|}
\hline \multirow{2}{*}{ AÑOS } & \multicolumn{2}{|c|}{ PROVINCIA } & \multicolumn{2}{|c|}{ NACION } & \multicolumn{2}{|c|}{ CAPITAL } \\
\hline & CIFRAS ABSL. & $\%$ & CIFRAS ABSL. & $\%$ & CIFRAS ABSL. & $\%$ \\
\hline 1935 & 1.036 & 6,54 & 150.648 & 6,10 & 52 & 4,53 \\
\hline 1936 & 605 & 3,81 & 138.710 & 5,55 & 49 & 4,15 \\
\hline 1937 & 165 & 1,03 & 143.339 & 5,68 & 21 & 1,73 \\
\hline 1938 & 248 & 1,55 & 113.020 & 4,43 & 37 & 2,96 \\
\hline 1939 & 827 & 5,16 & 143.680 & 5,57 & 92 & 7,17 \\
\hline 1940 & 1.673 & 8,86 & 215.790 & 8,47 & 117 & 8,86 \\
\hline 1941 & 1.891 & 8,69 & 189.631 & 7,29 & 116 & 8,77 \\
\hline 1942 & 1.292 & 8,06 & 187.457 & 7,14 & 122 & 8,99 \\
\hline 1943 & 966 & 6,01 & 173.954 & 6,56 & 109 & 7,83 \\
\hline 1944 & 1.106 & 6,86 & 187.643 & 7,01 & 100 & 7,00 \\
\hline 1945 & 1.034 & 6,40 & 192.481 & 7,12 & 106 & 7,23 \\
\hline
\end{tabular}

Fuente: INE y elaboración propia.

El final de la guerra, 1939, supuso una oleada de matrimonios diferidos por el conflicto, que elevó el índice anterior a 5,16 en la provincia y 7,17 en la capital, continuando el aumento en 1940, año en que se alcanza el techo de la nupcialidad en la provincia de Soria, saltando el eje de los 1500 con un tanto por mil $(8,86)$ idéntico al de la capital y superior al nacional $(8,47)$ con algunas décimas.

En efecto, la provincia de Soria mantiene en 1941 y 1942 unos indices de nupcialidad semejantes a los alcanzados en los primeros años de siglo 8,69 para la provincia y 8,77 para la capital en el primer año citado y 8,06 y 8,99 respectivamente, para el segundo y último año en alza, ya que 1943 marca el comienzo de una etapa de estancamiento con tendencia negativa.

Los años que median entre 1943 y 1960 , son de un moderado equilibrio que se mantiene en el eje de los 1.000 , con oscilaciones apenas apreciables y tasas superiores al $6 \%$ que preludian la decadencia y pro- 
gresiva despoblación de la provincia que marca su vértice negativo en 1964 en que desciende al eje de los 500, el tope más bajo alcanzado en el siglo, descontando el periodo critico de la guerra civil española. Es un hecho que impresiona por las fuertes repercusiones que entraña, en una población ya envejecida por una fuga constante del elemento humano.

La pequeña recuperación en 1965 no supone cambio decisivo alguno, en primer lugar porque no se mantiene más que dos años, cayendo en picado en el último censo (1970), en segundo lugar porque si cotejamos las cifras absolutas con las relativas en tantos por mil, observaremos que la despoblación es mayor y la crisis más aguda. 1964 arroja 495 matrimonios en la provincia, que suponen un índice de 5,60\%. En 1965 la cifra se eleva a 715 mientras el índice baja a 5,09 y al año siguiente a 700 y 5,03, respectivamente, no obstante el índice mínimo de nupcialidad provincial descontando los del $36-38$, se alcanza en 1970 con $4,88 \%$.

\section{Nupcialidad en la capital}

La nupcialidad en la capital soriana sigue más o menos de cerca la línea de la provincia, en cuanto que acusa los mismos sucesos al menos hasta el primer tercio de siglo. En efecto, quedan marcados en una leve inflexión de la gráfica los años correspondientes a la primera guerra mundial y a la pandemia gripal del 18 tras la leve recuperación de 1917. A un periodo de depresión demográfica, sucede otro de crecimiento, siguiendo una tendencia al equilibrio no conseguida en la mayor parte de los casos. En estas altas y bajas en la balanza de la población, distinguiremos aqui dos etapas netamente marcadas:

La primera abarca desde principios de siglo hasta el año 1940, inmediatamente después de la guerra civil. La segunda, arranca precisamente desde ese año de postguerra, hasta nuestros días. La línea divisoria es tan neta, tan radicalmente distinta, que resulta difícil creer que se trata de la misma ciudad.

Los años de baja nupcialidad en la primera etapa son, como hemos señalado anteriormente, los de período de guerra de 1914 a 1916, la epidemia de 1918, seguida de un nuevo bache en 1923, a resultas seguramente de las secuelas del anterior, y finalmente el más profundo de 1936-38 correspondiente a la guerra civil española. Se trata pues, de una línea dentada con pequeñas muescas que muerde el eje de los 50: 50- 
40, 50-60, alcanzando la cota más elevada (84) en 1928, y la más baja (21) en 1937.

A diferencia del gráfico provincial que sigue desde 1900 una tendencia claramente continuada de baja, en la capital, como hemos dicho, la balanza se sitúa en los 50, pero con tendencia alcista, sobre todo a partir de 1925 en que la sobrepasa excepto el paréntesis abierto en el trienio de la guerra civil, que da paso a la segunda etapa.

En esta segunda etapa señalada, se observan saltos sensacionales de censo a censo, siempre en línea ascendente, con algún ligero retroceso que estimula la recuperación acelerada. En el decenio 1940-50, las crisis se suceden cada cinco años si bien la de 1947 al 49 no se puede considerar como tal y la explicación en la baja se debería al contraste con el excesivo empuje de 1946.

Lo cierto es que en cifras absolutas se pasa de 117 en 1940 a 159 en 1950, con la baja del 1944 y 1945 establecida en 100 y 106 respectivamente, y la de los años que siguen al alza de 1946 (165) que rondan la línea de los 140.

En los 8 años que median de 1951 a 1958, la línea ascendente es casi vertical, ya que tan solo en cuatro años, se supera el eje de los 200 $y$ el de los 250 en los cuatro años siguientes.

La poderosa atracción que ejercen las ciudades sobre el campo, llevan aparejado el fenómeno del urbanismo como factor determinante en la demografía actual. El progreso que va unido a la mecanización sustituye en el campo la mano de obra humana por la máquina, iniciándose el éxodo a las ciudades intra o extraprovinciales que crecen desmesuradamente a marchas forzadas intentando potenciar al máximo la capacidad de asimilación para no ser desbordadas. En la provincia de Soria, el papel rector único y exclusivo ha sido adjudicado a la capital que ha visto multiplicar sus efectivos humanos de forma extraordinaria en el espacio de 20 años, sobrepasando la cota de nupcialidad de los 300 y doblando el tanto por mil que ha pasado de los 8 a los 15 y continúa en alza.

\section{Solteros: Provincia y capital}

Hasta el momento, hemos visto el movimiento de la nupcialidad en lo que va de siglo, en la capital y provincias sorianas, pero mayor interés tiene el hecho de saber con qué efectivos de solteros cuenta la provincia 
para calcular sus reservas y cual es la edad dominante en los matrimonios para deducir su potencia reproductora.

Partiendo de 1930, estudiaremos los censos de 1940, 1960, 1970 y 1981, distinguiendo tanto en la provincia como en la capital, los varones y mujeres en edad de matrimonio de los 20 años hasta los 54 , divididos en quinquenios sobre los que sacaremos el tanto por ciento.

PORCENTAJES DE SOLTEROS POR SEXOS Y GRUPOS DE EDADES

$\begin{array}{llllllll}\text { VARONES } & 20-24 & 25-29 & 30-34 & 35-39 & 40-44 & 45-49 & 50-54\end{array}$

Provincia:

$\begin{array}{rrrrrrrr}1930 & 96,03 & 47,40 & 17,02 & 8,80 & 6,39 & 4,41 & 5,20 \\ 1940 & 96,23 & 70,04 & 31,12 & 14,32 & 10,24 & 6,21 & 5,22 \\ 1960 & 97,24 & 66,78 & 32,99 & 18,12 & 13,53 & 11,84 & 9,66 \\ 1970 & 97,91 & 70,65 & 39,65 & 25,05 & 18,36 & 13,23 & 11,13 \\ 1981 & 94,33 & 61,80 & 37,60 & 29,99 & 25,00 & 19,55 & 16,08\end{array}$

Capital:

$\begin{array}{rrrrrrrr}1930 & 96,31 & 53,08 & 24,41 & 20,37 & 14,52 & 11,35 & 12,90 \\ 1940 & 97,38 & 70,55 & 36,72 & 15,13 & 12,88 & 14,55 & 10,13 \\ 1960 & 94,56 & 58,92 & 26,49 & 14,35 & 9,49 & - & - \\ 1970 & 40,67 & 23,37 & 9,53 & 6,58 & 4,89 & 2,16 & 2,30 \\ 1981 & 88,67 & 45,56 & 23,21 & 14,30 & 12,28 & 11,09 & 12,55\end{array}$

Provincia:

$\begin{array}{rrrrrrrr}1930 & 71,10 & 30,38 & 15,73 & 10,25 & 8,30 & 6,00 & 5,59 \\ 1940 & 84,30 & 45,96 & 22,82 & 13,86 & 10,82 & 7,83 & 7,47 \\ 1960 & 81,80 & 43,15 & 22,61 & 16,80 & 14,75 & 13,85 & 9,79 \\ 1970 & 86,39 & 45,56 & 23,20 & 15,15 & 14,92 & 14,70 & 13,62 \\ 1981 & 79,12 & 40,31 & 19,15 & 13,54 & 16,77 & 8,10 & 13,25\end{array}$

Capital:

\begin{tabular}{|c|c|c|c|c|c|c|c|}
\hline 30 & - & 48,72 & 28,92 & 29,69 & 23,44 & 20,37 & 91 \\
\hline 94 & 87 & 59,60 & 39 , & 29,81 & 23,8 & 22,85 & 19,75 \\
\hline & 67 & 44,38 & 29,46 & 24,93 & 18,79 & - & - \\
\hline$y$ & 77 & 40,19 & 20,82 & 17,24 & 20,54 & 16,48 & 18,63 \\
\hline & 73,2 & 35,00 & 15,21 & 14,65 & 17,84 & 15,87 & 19,38 \\
\hline
\end{tabular}

Fuente: INE y elaboración propia. 
Según Barceló Pons, de las tablas expuestas puede deducirse, que a partir de cierta edad, que oscila para los varones sobre los cuarenta y cinco y para las hembras igual o entre treinta y cinco y cuarenta años, los matrimonios entre solteros son despreciables, si bien la solteria definitiva no se da hasta los cuarenta y cinco y cincuenta años. A partir de esta edad los porcentajes de solteros resultan poco representativos, por intervenir la mortalidad diferencial que juega un papel perturbador (discriminante).

El porcentaje de solteros, normalmente, está en relación directa con el grado de desarrollo económico-social. En los países subdesarrollados aparece una precocidad mucho más fuerte que en los países desarrollados. Sin embargo cuando se alcanza cierto nivel de desarrollo, intervienen en el porcentaje de solteros otros factores, como las guerras, las crisis económicas, ciertas costumbres, etc., que perturban la nupcialidad, dejando su huella en una generación determinada, dando lugar a anomalias.

De la comparación de los cuadros anteriores, se deduce el elevado grado de soltería, tanto entre los varones como en las hembras, y las diferencias que presenta la provincia con la capital.

En la evolución de la proporción de solteros en los distintos censos, observamos que en el año 1940 se da un máximo en ambos sexos, en los tres primeros grupos de edad, hasta 35 , hecho motivado por una parte, por la guerra civil, que retrasó la celebración de muchos matrimonios, y por otra a la fuerte inmigración de solteros que se produjo una vez terminada la contienda y cuyo estado civil obedecía a las mismas razones.

Desde 1940, la proporción de solteros desciende entre los varones, y sobre todo entre las mujeres, que alcanzan en 1965 los mínimos de todo el siglo en los grupos de hasta cuarenta años. Es decir, hay una intensificación de la nupcialidad que ha de relacionarse con una elevación del nivel de vida y con la inmigración de matrimonios.

El predominio de mujeres solteras sobre el de varones es patente sobre todo en la capital, que presenta los porcentajes más elevados según la edad al contraer matrimonio entre los varones de veinticinco a treinta años.

El aumento en el porcentaje de la solteria entre 1970-1981 estaria motivado entre otras razones por el período de crisis económica que tuvo su origen en la crisis del petróleo de 1973, y por un cambio de tendencia general en la formación de parejas, debida a la incorporación de la mujer 
al mercado de trabajo remunerado, hecho que retrasa la edad matrimonial.

\section{LA EMIGRACIÓN: INTRODUCCIÓN}

La emigración constituye el fenómeno sociológico más importante de nuestro tiempo. El desplazamiento humano a veces masivo, fuera de los límites provinciales e incluso nacionales, ha sido y es continuamente objeto de estudio por parte de historiadores, sociólogos, economistas y en general todos cuantos se relacionan con el problema. "La primera verdad evidente es que los movimientos migratorios no pueden estudiarse aislados; son un fenómeno demográfico comprensible tan solo como toda la demografía, cuando se lo considera dentro de un cuadro, muy complejo de circunstancias sociales, económicas y políticas que podemos englobar dentro del nombre de coyuntura histórica"... (CASAS TORRES 1958) "que sean espontáneos, solicitados o forzosos, temporales o permanentes, interiores o exteriores, 0 , por partes, todas estas cosas a la vez, dependerá siempre de las circunstancias de la coyuntura histórica obrando a través de los fenómenos demográficos" '.

En Castilla el hecho migratorio y en último término despoblador, obedece efectivamente como decíamos antes, a unos factores políticos, sociales y económicos que han jugado respectivamente desde principios y desde mediados del quinientos.

\section{Antecedentes históricos}

La emigración al Nuevo Mundo comenzó casi inmediatamente después del descubrimiento y fueron numerosísimos los emigrantes que con licencia (una minoria) o sin ella, embarcaron año tras año en las flotas de Indias. Las cifras oscilan bastante de unos autores a otros. Carande ${ }^{3}$ partiendo de los catálogos oficiales de pasajeros habla de 21.365 durante

1 Casas TORRES, “Planteamiento general. Los movimientos migratorios en la $\mathrm{H} .{ }^{a}$ y en la actualidad mundial», págs. 23-40. Semanas sociales de España. XVIII semana. VigoSantiago 1958.

3 Carande, "La vida económica en Castilla», pág. 69. 
el período 1509-1559, cifra a la que habría que añadir la emigración ilegal muy numerosa por otra parte. Nadal ${ }^{4}$ dice que "para cobrar su auténtico significado, la emigración a América debe referirse no a todo el potencial humano español, sino al de una parte de la Corona de Castilla". Según esto vamos a ver que lugar ocupan Soria y las provincias del Sistema Ibérico en este movimiento migratorio.

\section{PROCEDENCIA DE 7.645 EMIGRANTES A AMÉRICA, EMBARCADOS EN SEVILLA DURANTE EL PERIODO 1509-1534 ${ }^{5}$.}

\begin{tabular}{|c|c|}
\hline PROVINCIAS & EMIGRADOS \\
\hline $\begin{array}{l}\text { Soria } \ldots \ldots \ldots \ldots \ldots \ldots \ldots \ldots \\
\text { Guadalajara } \ldots \ldots \ldots \ldots \ldots \ldots \ldots \\
\text { Cuenca } \ldots \ldots \ldots \ldots \ldots \ldots \ldots \ldots \\
\text { Teruel } \ldots \ldots \ldots \ldots \ldots \ldots \ldots \ldots\end{array}$ & $\begin{array}{l}78 \\
91 \\
45 \\
10\end{array}$ \\
\hline$\ldots \ldots \ldots \ldots \ldots \ldots \ldots$ & 224 \\
\hline
\end{tabular}

Estos, como otros datos anteriores, ponen de manifiesto el paralelismo existente entre Soria y Guadalajara en cuanto a evolución de la población en ambas provincias. El factor decisivo que marca fundamentalmente las diferencias entre las provincias del Sistema Ibérico, es su mayor o menor proximidad respecto al centro de la peninsula. Teruel iniciará más tarde el camino de la emigración aún cuando la aceleración en el proceso de despoblamiento haya suplido con creces esta incorporación tardía en el campo migratorio.

Las cifras apuntadas por Céspedes del Castillo ${ }^{5}$, forman parte de un informe de 48 provincias en las que Soria ocupa el lugar 24 en orden a la importancia de los efectivos emigrados, a Guadalajara le corresponde el 21 , a Cuenca el 29 y finalmente el 42 a Teruel.

Otra de las sangrías demográficas, fueron la conquista, defensa y administración de las posesiones extrapeninsulares que exigieron un gran contingente humano difícil de evaluar. De 1635 a 1659, los territorios de

\footnotetext{
${ }^{4}$ NADAL, op cit., pág. 63.

"Cespedes del Castillo, G., en "Historia Social y Económica de España y América", dirigida por J. Vicens Vives, t. III, pág. 394.
} 
Castilla fueron sometidos a un sistema de levas casi ininterrumpidas que acabaron con sus últimas reservas.

La segunda corriente en dirección a América se inició más tarde, pero fue mucho más importante. Esta vez se trataba de América del Sur, en la que acababan de estrenar su independencia las jóvenes naciones americanas y necesitaban para la explotación de sus inmensas riquezas hacer uso de una política demográfica generosa, basada en la atracción de extranjeros. En este sentido marcó la pauta la constitución argentina de 1853 que abrió ampliamente las puertas a la inmigración. De 1857 a 1915 desembarcaron en Argentina 1.497 .741 españoles. El movimiento de tendencia acelerada alcanzó un auge extraordinario en los primeros años del siglo actual, favorecido sobre todo por la prohibición de embarque en aquella dirección que hizo el gobierno italiano a sus pobladores en 1912.

Esta corriente, decayó durante la guerra europea y a partir de las medidas restrictivas de 1930 .

De todas formas, la tendencia migratoria de la provincia de Soria nunca se manifestó por sus salidas a ultramar. La emigración a Argentina y más tarde (1887) al Brasil que sustituyó en importancia a la primera por sus efectivos humanos en el saldo migratorio sobre todo a partir de 1908 , en que se sustituyeron los antiguos colonos alemanes y suizos preferidos hasta entonces, por emigrantes latinos, sobre todo españoles, no contaron con la aportación numerosa de sorianos, sin embargo nos consta según Nadal ${ }^{6}$ que en el decenio de 1877 a 1887, las pérdidas de población afectaron a Álava, Almeria, Navarra, Pontevedra, Soria y Teruel. El censo de 1900 arrojó con respecto al de 1887, una nueva composición y extensión del área despoblada: Baleares, Gerona, Guadalajara, Huesca, Lérida, Málaga, Orense, Soria y Pontevedra.

\section{Evolución del proceso migratorio en Soria}

La provincia de Soria figurará ya de modo permanente en las listas de despoblación desde 1900 hasta el último censo en que sigue la misma tónica descendente, participando en el saldo migratorio nacional a otros paises.

\footnotetext{
6 NadAl, op cit., pág. 209 y ss.
} 
En treinta y tres años (1882-1914) según estadísticas de pasajeros salidos por mar, España perdió cerca de un millón de habitantes, equivalentes a 1/3 parte del incremento nacional, y eso suponiendo que la cifra es inferior a la realidad, ya que el embarque se hacia a veces en puertos portugueses 0 franceses.

Más difícil es el estudio de la emigración por provincias, ya que hasta 1962 no contamos con datos estadísticos del INE distinguiendo sexo, profesión del emigrante, puntos de destino y medios de transporte que emplea. Datos, que si bien reflejan de forma bastante completa la aceleración del proceso migratorio en la última década, dejan sin cubrir una parte muy importante, como es, la del proceso seguido desde principios de siglo hasta los años 60 .

Asi estudiamos la evolución histórica del saldo migratorio provincial a través de métodos indirectos, estableciendo la diferencia entre el crecimiento vegetativo y el intercensal, partiendo de 1900 hasta 1981.

LOS MOVIMIENTOS MIGRATORIOS PROVINCIA DE SORIA

\begin{tabular}{c} 
PERIODO \\
INTERCENSAL NACIMIENTOS DEFUNCIONES $\begin{array}{c}\text { CRECIMIENTO } \\
\text { VEGETATIVO }\end{array}$ CRECIMIENTO \\
INTERCENSAL PORDIDA \\
\hline
\end{tabular}

\begin{tabular}{llrrrr}
$1900-1910$ & 64.901 & 46.831 & 18.070 & +5.892 & 12.178 \\
$1911-1920$ & 50.764 & 38.884 & 11.880 & -4.759 & 16.639 \\
$1921-1930$ & 48.596 & 31.228 & 17.368 & +4.612 & 12.756 \\
$1931-1940$ & 41.755 & 27.036 & 14.719 & +3.617 & 11.100 \\
$1941-1950$ & 36.837 & 21.139 & 15.798 & +1.357 & 14.441 \\
$1951-1960$ & 28.689 & 15.914 & 12.775 & -14.129 & 26.904 \\
$1961-1970$ & 19.379 & 13.034 & 6.345 & -32.096 & 38.441 \\
$1971-1981$ & 11.813 & 10.613 & 1.200 & -16.743 & 41.244 \\
\hline
\end{tabular}

Fuente: INE y elaboración propia.

1. ${ }^{\text {er }}$ periodo migratorio

A primera vista, se observan dos procesos de descenso dentro de la marcha general migratoria. El primero, entre los años 1911 a 1920, en que el saldo por emigración es netamente superior a los períodos intercensales anterior y posteriores, con una pérdida de 16.639 personas es consecuencia de la primera guerra mundial y la posición de neutralidad que mantuvo nuestra península durante la contienda. 
Ya hemos explicado en páginas anteriores, como a un corto auge de exportaciones masivas a los paises beligerantes, sucedió la paralización comercial exterior y un stock de productos sobrantes difíciles de dar salida. Consecuencia de esto, que hundió a buena parte de los pequeños agricultores, los forzó a emigrar de sus tierras bien sea a ciudades españolas bien al extranjero, es el comienzo del desequilibrio demográfico de las regiones y el viraje brusco en la dinámica del movimiento natural de la población.

Aunque la guerra termina en 1918, muchos de sus efectos se prolongan indefinidamente. En España la ruptura del equilibrio más o menos estable entre el campo y la ciudad, será un hecho irremediable. La población netamente rural que en 1910 sumaba el $47,7 \%$ del conjunto, descenderá a 43,3 en 1920, continuando el descenso que ha beneficiado especialmente a las localidades mayores de 100.000 habitantes.

Así se pasó del $11,9 \%$ en 1920 al 27,8 en 1960 . No existen grupos intermedios, ya que han ido cediendo posiciones de manera constante en favor del grupo superior minoritario, por lo que podemos afirmar con Nadal ${ }^{7}$ que "el movimiento migratorio dirigido primero hacia las capitales de provincia, se ha concentrado luego en un número reducidísimo de grandes ciudades". Las principales entidades de la provincia de Soria no son una excepción en esta dinámica peninsular, sino por el contrario, parte muy implicada por el carácter agrícola de su economía.

SALDO EN LOS PARTIDOS JUDICIALES

\begin{tabular}{|c|c|c|c|c|c|c|c|}
\hline MUNICIPIOS & $\begin{array}{l}1900- \\
1910\end{array}$ & $\begin{array}{l}1911- \\
1920\end{array}$ & $\begin{array}{l}1921- \\
1930\end{array}$ & $\begin{array}{l}1931- \\
1940\end{array}$ & $\begin{array}{l}1941- \\
1950\end{array}$ & $\begin{array}{l}1951- \\
1960\end{array}$ & $\begin{array}{l}\text { TOTAL } \\
1900- \\
1960\end{array}$ \\
\hline $\begin{array}{l}\text { Agreda .......... } \\
\text { Almazán ........ } \\
\text { Burgo de Osma } \\
\text { Medinaceli ....... } \\
\text { Soria ........... }\end{array}$ & $\begin{array}{r}-754 \\
-2.542 \\
-3.614 \\
-1.368 \\
-3.272\end{array}$ & $\begin{array}{l}-3.784 \\
-2.844 \\
-3.400 \\
-1.390 \\
-5.221\end{array}$ & $\begin{array}{l}-1.591 \\
-2.676 \\
-5.349 \\
-1.066 \\
-2.074\end{array}$ & $\begin{array}{r}-3.467 \\
-1.872 \\
-3.735 \\
-1.229 \\
-805\end{array}$ & $\begin{array}{l}-2.513 \\
-3.561 \\
-4.390 \\
-2.338 \\
-1.538\end{array}$ & $\begin{array}{l}-3.809 \\
-5.623 \\
-6.613 \\
-4.161 \\
-6.507\end{array}$ & $\begin{array}{l}15.918 \\
19.118 \\
27.101 \\
11.552 \\
19.417\end{array}$ \\
\hline
\end{tabular}

Saldo provincial $-11.550-16.639-12.756-11.108-14.340-26.71393 .106$

Fuente: INE y elaboración propia.

\footnotetext{
7 NADAL, op. cit., pág. 175.
} 
Asi vemos, que en este primer proceso de descenso (1911-20) senalado con la primera guerra europea, Agreda y Soria arrojan por sí solas más de la mitad del saldo migratorio en todos los partidos judiciales, con 3.784 emigrantes en la primera y 5.221 en la capital. Para el partido judicial de Agreda, supone un duro golpe ya que significa multiplicar por cinco la emigración del decenio anterior. En el partido de Soria, esta cifra solo se verá superada a partir del descenso general de los años 50 en que la emigración a las ciudades se convertirá en una huida en masa de la pobreza.

Almazán, Burgo de Osma y Medinaceli mantienen más o menos los efectivos migratorio anteriores rebasando la cifra de los 2.500 los dos primeros (2.844 Almazán, 3.400 Burgo de Osma) y de 1.000 el tercero.

El decenio de 1921 a 1930 , no supuso variación importante en el proceso migratorio, sino simplemente un freno temporal en la activa marcha emprendida con la guerra europea. Las cifras alarmantes en el partido de Agreda, descendieron, y en cambio Burgo de Osma alcanzó la cifra de 5.349 emigrantes. Puede decirse a la vista de los datos expuestos, que el Burgo es el foco emisor más fuerte de la provincia de Soria ya que de 1900 a 1960 salieron de su partido 27.101 personas. Le siguen Almazán y la capital que superan los 19.000 emigrantes, Agreda arroja la cifra de 15.908 y por último Medinaceli con 11.552 .

\section{2. ${ }^{\circ}$ período migratorio}

Anteriormente habiamos señalado dos procesos de descenso, el primero ya comentado, se iniciaba en la primera guerra mundial; el segundo, con la guerra española del 36 al 39 cuyos efectos se reflejan en el decenio 1941-1950, con 14.340 emigrantes en los partidos judiciales destacados. El nuevo ciclo migratorio se caracterizó por rebasar el área francesa, extendiéndose a otros paises europeos como Alemania, Suiza, Austria, Países Bajos y Bélgica, aunque los emigrantes sorianos se dirigieron con marcada preferencia a los tres primeros paises señalados, esto es: Francia, Alemania y Suiza.

A partir de 1938 y en virtud de los numerosos exiliados políticos, la cifra de emigrados aumentó considerablemente. En los años 40 y 50, la emigración era a las capitales de provincia, bien a la propia provincia 0 a otras más industrializadas.

En los años 60, la dirección migratoria era directamente enfocada hacia el extranjero. Muchos, según la edad, pasaron por las dos ya que el desarraigo que suponía cortar las amarras del propio pueblo les capa- 
citaba para dar el salto mayor. Los más jóvenes pasaron por la segunda opción directamente.

El paro y la precariedad económica que siguieron a nuestra guerra civil y al bloqueo económico posterior, sirvieron de acicate a la emigración si bien en principio tuvo un carácter marcadamente interior por la dificultad de conseguir visados para salir al extranjero y por el conflicto mundial que estalló a continuación.

En las capitales de provincia, el proceso migratorio queda paliado por la atracción que ejercen las mismas sobre gran número de municipios y por la ampliación de su propio radio de acción como capital que va englobando o absorbiendo poco a poco los municipios más próximos tanto por su expansión natural como por el acortamiento de distancias gracias a la mejora de las vias de comunicación y medios de transporte.

\section{Emigración exterior}

Efectivamente, la corriente migratoria española a Europa que alrededor de los años de la primera guerra mundial alcanzó un flujo considerable de trabajadores dirigidos principalmente a Francia (146.446 antes de 1918 contra 350.000 en 1918) se vio incrementada a raíz de nuestra guerra civil con un potencial de 800.000 españoles censados en 1939 , cifra tope representantiva tan solo de las circunstancias especiales en que se daba y considerando que el país vecino servía de escala o trampolín hacia otros destinos dentro o fuera del continente.

La movilización general de los varones franceses en edades productivas, hizo que una parte de este contingente migratorio, encontrase trabajo preferentemente en el sector agrícola, tal como habia ocurrido en el primer conflicto europeo en que la población española llegó a representar el $16 \%$ del total de la población extranjera, asi en 1946, el número de españoles en Francia era de 802.000 , cifra elevada teniendo en cuenta el total migratorio español, de tal forma que podía considerar si no el único canal, si el más importante, valorando para ello el hecho de que por una parte, la política migratoria francesa de los últimos 25 años se inscribe en una línea bastante permisiva con arreglo a otros paises europeos receptores como Alemania o Suiza por citar los más importantes respecto a la corriente migratoria española al exterior y por otra, al matíz demográfico especial aparte de la raiz claramente económica que tenga como los demás países, evidenciado gráficamente en la pirámide de edades que señala la mayoria absoluta de población vieja, regresiva, y la 
necesidad perentoria de repoblación. La Oficina Nacional de Inmigración (ONI) se creó para solucionar toda esta serie de problemas demográficoeconómicos en 1945 y desde esta fecha hasta 1972 en que las cosas cambian de signo, ha seguido una política bastante abierta, dentro de las limitaciones naturales.

Paralelamente en el resto de Europa, se va desarrollando una política similar de reconstrucción e industrialización, sobre todo en aquellas naciones más afectadas por la segunda guerra mundial, como es el caso de Alemania. Desde 1954, las estadísticas alemanas consignan que el fenómeno de la emigración extranjera empieza a ser considerable. Los españoles aumentan primero discretamente, desde 400 que se contabilizan en este año, hasta 1.000 en 1957, pero al entrar en la nueva década, la cifra se multiplica casi por 30 en los dos años siguientes y en sucesivos que comentaremos en su momento.

En Suiza, durante el periodo de entreguerras, la legislación sobre extranjeros fue altamente restrictiva, y solo con el «boom» de la posguerra volvió a crecer el número de autorizaciones hasta alcanzar el techo a partir del periodo 1954-58 en que el total de extranjeros llegarán a representar el $18 \%$ de la población total.

Al despegue migratorio español dentro de las corrientes migratorias mundiales como fenómeno de nuestro tiempo, contribuyó de manera decisiva la creación el 17 de julio de 1956 del Instituto Español de Emigración (IEE) que estableció las condiciones de emigración al exterior, mediante la firma de acuerdos bilaterales con los principales países receptores. La mejora de las condiciones, laborales del trabajador y el respaldo de unas garantías jurídicas antes inexistentes, favorecieron la salida del país y el control de la misma, aunque haya que contar con numerosas limitaciones a la hora de consignar una salida "real», ya que las diferencias estadisticas que existen por ejemplo entre las fuentes españolas y las del pais receptor, radican en que el IEE compute solo los emigrantes asistidos por él, mientras que todos los falsos turistas y emigrantes clandestinos, quedan fuera de cuentas.

"La edad de los emigrantes ${ }^{8}$ oscila entre veinticinco y treinta y cuatro años que representa el más alto porcentaje, tanto para varones $(49,46 \%)$ como para mujeres $(36,46 \%)$. El escaño que le sigue es el comprendido entre los dieciséis y los veinticuatro años, que supone un

"SANChez LOPEZ, Francisco, "Emigración Española a Europa". Madrid, Confederación española de Cajas de Ahorro, 1969, págs. 87-88. 
$24,40 \%$ de los varones y un $43,57 \%$ de las mujeres. En último lugar, señalaremos la edad comprendida entre los treinta y cinco y cuarenta y cuatro años que tiene aún un alto porcentaje masculino $(23,71)$ pero mucho más bajo el femenino $(16,27)$ ".

La ocupación principal suele centrarse en los sectores de la construcción, metalurgia, automóviles, servicios públicos, servicios domésticos, hostelería y agricultura, apartado este último en el que hay que contabilizar los temporeros sobre todo en Francia.

En su mayor parte se trata de obreros sin cualificar (peones) o con una cualificación elemental, difícil de superar ya que la mano de obra interesa en tanto que peonaje sin cualificar, si no, interesa menos.

Estadísticamente, Galicia y Andalucia se turnan en la primacia de Contingentes migratorios en el exterior coincidiendo con una bajisima renta "per cápita" en ambas provincias y con una fuerte tasa de natalidad.

Las provincias del Sistema Ibérico y más concretamente Soria, no aparecen en las listas de las diez provincias de más saldo migratorio exterior, participando sin embargo de lleno en la emigración interior, sobre todo, a partir de los años cincuenta.

Tamames ha calculado que entre 1950 y 1960, más de un millón de personas se desplazaron desde las dos mesetas, Extremadura y Andalucia a los suburbios de Madrid y de las ciudades industriales del Norte y de Cataluña.

La avalancha se produjo como consecuencia de la situación estacionaria en la agricultura y de rápida expansión en la industria y en los servicios que motivaron una huida en cadena de la población de las zonas agricolas a aquellas en que la instalación de industria y servicios, ofrecia mejores posibilidades de trabajo. De todo el conjunto nacional, trece provincias emisoras resultaron tan afectadas por este fenómeno migratorio que su población disminuyó de forma alarmante en términos absolutos.

Emigración continental de la provincia de Soria

La emigración continental de la Provincia de Soria se dirige fundamentalmente en tres corrientes: Alemania, Francia y Suiza, con una directriz clara hacia el pais vecino hasta 1965. En 1963 emigraron un total de 92 personas a Francia, de ellas 61 varones solteros y 26 casados, sobre tres mujeres solteras y dos casadas. En este mismo año, Alemania 
dio un total de 83 con una distribución por estado civil semejante a la francesa: Una mayoría de solteros, esta vez a favor del elemento femenino: 25 varones y 40 mujeres, y nueve varones y mujeres casados. Suiza rebajaba el saldo a la mitad de la emigración a Francia y la misma situación se mantuvo el año siguiente. En 1965 se da un cambio de signo: Sube el contingente migratorio suizo mientras el francés sufre una regresión, en cualquier caso, disminuye en general en dos tercios la emigración continental en los tres paises señalados: Francia da un total de 12 personas, 11 varones y una mujer: cuatro varones solteros, siete casados y una mujer casada también. Alemania rebaja el saldo total a 20 y Suiza a 27. Y a partir de 1966 hasta 1970, el saldo a Francia dificilmente supera los seis emigrantes y Alemania y Suiza oscilan entre los 15 y los 20 hasta 1970 en que Alemania alcanza los 56. Suiza 39 y Francia dos. El porcentaje más alto lo dan los varones solteros, seguido de los casados. La incorporación de la mujer a la emigración es lenta y regresiva en el caso de la provincia de Soria.

En cuanto a las profesiones, el contingente migratorio se reparte desigualmente, un $50 \%$ lo integran artesanos, trabajadores industriales y peones, un $35 \%$ está dedicado a la agricultura, pesca, caza y trabajos forestales y asimilados y el $15 \%$ restante se reparte entre las mujeres sin profesión y niños menores de 14 años. La edad de estos trabajadores distribuida de cinco en cinco años a partir de los 14, nos da la primacía para el grupo de 25-29, seguido del de los 20-24 años de edad y de los 30-34.

De los 40 en adelante, hasta el tope de los 55 , el porcentaje de emigrantes apenas es significativo.

La emigración a ultramar supone un contingente mínimo dentro de la corriente migratoria provincial: Canadá, Argentina, Australia, EE.UU por este orden, son los principales paises receptores de una emigración compuesta en su mayor parte de trabajadores solteros con un grado de enseñanza primaria.

Del período 1962-70, el año de máxima emigración fue 1966 con una partida de 43 personas de las que 22 embarcaron al Canadá. El medio de transporte más utilizado fue el barco, del orden de 2/3 del total migratorio a ultramar, sobre $1 / 3$ que se desplazó por vía aérea.

De todas formas, la tendencia general cambió a partir de 1965 cuando los precios del pasaje descendieron con bonificaciones y rebajas por distintos conceptos. El saldo migratorio de la provincia de Soria a Ultramar en estos diez últimos años hasta 1970, es tan bajo (157 personas) que su distribución en distintos medios de transporte, apenas es signifi- 
cativa. En cifras generales, el Instituto Nacional de Emigración contabilizó 7.881 emigrantes a ultramar durante 1970, de los cuales 2.068 salieron via marítima y 5.813 por vía aérea. La cifra total de migración supone un $30,7 \%$ menos con respecto a la del año anterior, lo que demuestra la crisis profunda por la que atraviesa la Emigración Transoceánica española. En este mismo año, la emigración por vía marítima ha sufrido una disminución del 58,6\% en relación a la correspondiente de 1969 lo mismo que la aérea aunque los porcentajes no sean tan elevados. Emigran fundamentalmente los hombres en número creciente, mientras decrece el de mujeres. De todas formas es claro que ha habido un descenso general de la emigración española en todos los campos a partir de 1970.

Efectivamente es significativo que desde 1970, aumente en nuestro país, el número de emigrantes marroquies y portugueses que vienen a cubrir los puestos de trabajo de peonaje sin cualificar, que dejaron nuestros propios emigrantes. Es significativo por cuanto sirve de termómetro indicador, en primer lugar, de un mayor grado de desarrollo económico que estimule a nuestros vecinos más atrasados y en segundo lugar, de la rentabilidad de las divisas de nuestros trabajadores en el extranjero que después del turismo, vienen a ser en importancia, la segunda fuente de ingresos a escala nacional.

Actualmente la emigración es prácticamente nula, o por lo menos tal y como se ha venido desarrollando en los últimos años. Sí se ha seguido manteniendo la tónica general en la emigración a ultramar, siendo en el período de 1971-1981 de 48 personas.

Por otro lado la emigración interior ha caído en picado desde el año 1971, con 1.636 emigrantes, hasta 1.297 en 1983. Sin embargo en la serie de años se descubren dos momentos de alza, el año 1974, con 2.868 emigrantes y el mismo año 1983, después del año 1981 con tan solo 585 .

Los centros de atracción siguen siendo, en 1983, y por este orden:

$\begin{array}{lr}\text { Soria capital } \ldots \ldots \ldots \ldots \ldots \ldots & 433 \\ \text { Madrid } \ldots \ldots \ldots \ldots \ldots \ldots \ldots & 184 \\ \text { Zaragoza } \ldots \ldots \ldots \ldots \ldots \ldots \ldots & 141 \\ \text { Barcelona } \ldots \ldots \ldots \ldots \ldots \ldots \ldots & 58 \\ \text { Logroño } \ldots \ldots \ldots \ldots \ldots \ldots \ldots & 40\end{array}$

En la década de los 80 , hemos pasado a ser un país receptor de 
emigrantes, lo que confirma la tendencia iniciada en los años 70 , de nuestro progreso económico. Sin embargo Soria se mantiene al margen de esta corriente, manteniendo su carácter migratorio.

INDICADORES ECONÓMICOS DE SORIA

\begin{tabular}{|c|c|c|}
\hline & $\begin{array}{l}\text { AÑO } 1981 \\
\text { (MILLONES) }\end{array}$ & $\begin{array}{l}\text { ANNO } 1983 \\
\text { (MILLONES) }\end{array}$ \\
\hline Ingresos totales & 29.346 & 42.855 \\
\hline Per cápita ..... & 0,291 & 0,430 \\
\hline Renta familiar & 27.658 & 39.409 \\
\hline Per cápita .... & 0,275 & 0,396 \\
\hline
\end{tabular}

\section{ESTRUCTURA DE LA POBLACIÓN}

La composición de la población por edades y sexos. Comentario a las pirámides de población en la provincia y en la capital

Toda pirámide de edad es un reflejo gráfico del efectivo demográfico, cuyo desarrollo está ligado a la fecundidad y mortalidad, entrando los movimientos migratorios como tercer factor, fundamental con los anteriores en la configuración del perfil de una pirámide.

Atendiendo a las edades, la principal caracteristica de la composición demográfica de la provincia de Soria, es el elevado porcentaje que presentan las personas mayores de cincuenta años. Este proceso de envejecimiento de la población, se ha llevado a cabo paulatinamente y de forma inexorable desde principios de siglo hasta la actualidad sin que por el momento haya frenado su marcha.

La existencia de un bajo porcentaje de menores de cinco años, sensiblemente inferior al que se presenta en el conjunto nacional, se explica, si consideramos que se trata de un estrato de edad, frecuente entre los hijos de los emigrantes encuadrados entre los 20 y los 35 años.

Es un hecho generalmente conocido, que a escala nacional existe un cierto predominio de las mujeres en la composición de la población, 
predominio que resulta más marcado, si se considera por separado la población que vive en las capitales. La de Soria no es una excepción y el resultado es que en 1965 existían un $54,1 \%$ de mujeres frente $45,9 \%$ de varones por eso las muescas en los bloques femeninos, serán siempre menos acusadas que en los masculinos; las pendientes más regulares, indicarán por otra parte, una menor movilidad de la población femenina. Ahora bien, es preferible examinar una a una las pirámides de población de la provincia y de la capital, y deducir las conclusiones que se desprendan de su estudio particular. Comenzaremos por la provincia a partir ${ }^{9}$ de 1900 .

\section{Las pirámides provinciales}

Para la construcción de esta pirámide, así como para las de 1910 y 1920 , se han tomado datos por grupos de 10 años, ajustándonos a los

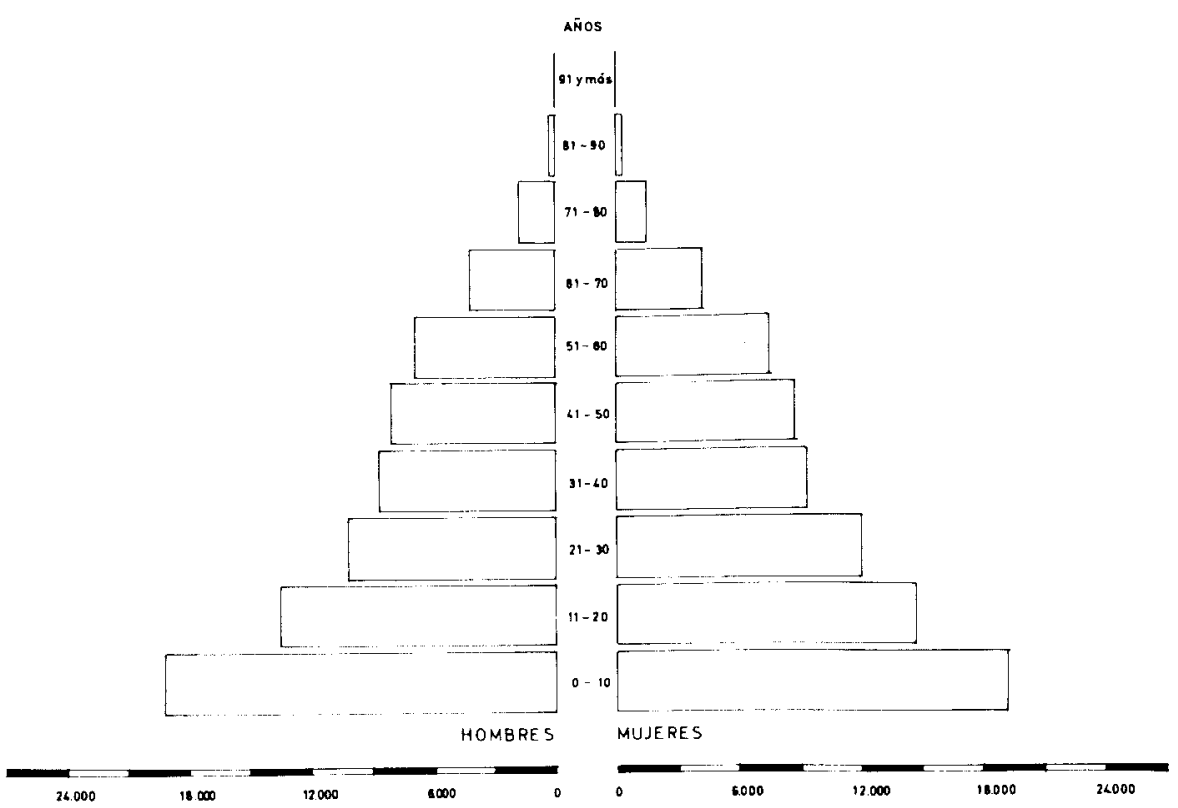

Fig. 6. Composición de la población por edades y sexo. Provincia 1900

${ }^{9}$ Confederación Española de Cajas de Ahorros, Madrid. "Desarrollo de la Agricultura y Ganadería sorianas". T. I., pág. cit. 85. 
censos; ello resulta más inexpresivo, pero nos permite formar una primera idea sobre el estado de la población en este año.

Observamos en la pirámide, una base amplia, equiparada en ambos sectores, que corresponde a una natalidad de tipo medio. La mortalidad infantil se aprecia en la diferencia del primer al $2 .^{\circ}$ brazo, bastante marcada en ambos sectores en los que supone que el mayor potencial de bajas se dará en los primeros años, incluso se observa más elevado en el masculino, cosa lógica en las primeras edades. La tónica de descenso de población, continua en toda la pirámide de forma gradual, de tal forma que solo los tres primeros brazos presentan escalones marcados que se estabilizarán de los siete a los 9.000 tanto en hombres como en mujeres de los 30 a los 60 años. El escalón de los 30 a los 40 , marcado sobre todo en el sector femenino puede deberse, a la elevada mortalidad postparto de la mujer en edad de procrear, debido a la falta de higiene principalmente. De los 60 a los 70 años, el potencial demográfico se iguala y queda reducido a la mitad, pasando de las 6.000 a las 3.000 personas en ambos sectores de 70 a 80 años, aunque la pérdida se aprecie más en el femenino. Se trata de los últimos peldaños de la pirámide.

La pirámide de 1920 , presenta una gran regularidad comparando la amplitud de los dos sectores.

La diferencia notable entre el primer y $2 .^{\circ}$ brazo se debe a la mortalidad infantil, todavía alta en los primeros años de vida; diferencia equiparable a la del segundo y tercer brazo, aunque por distinta causa, en este caso es por la fuerte emigración que caracteriza a la provincia desde antiguo y sobre todo, por una causa extraordinaria: la pandemia gripal que en 1918 asoló España. El resto de la pirámide no ofrece contrastes notables y disminuye con regularidad. La edad media de vida de menor alcance que la actual, se aprecia en estos primeros años de siglo, por el descenso palpable en los últimos brazos de la pirámide a partir de los 70 años de edad, la disminución es rapidisima. Se trata pues en conjunto de una pirámide típica de país subdesarrollado, poco evolucionado, tradicional, con elevado número de nacimientos, y escasa población activa de edad media, que tiene que alimentar una población senil diezmada y en contraste a un elevado potencial infantil.

La evolución en los dos sectores masculino y femenino es prácticamente paralela, salvo la base de la pirámide y el segundo brazo de gran amplitud, el resto que engloba edades de 20 a 60 años en número escaso, con diferencias apenas significativas, alcanza casi seguidamente el grupo senil fuertemente disminuido por la mortalidad elevada. El sector femenino mucho más destacado en cuanto a efectivos humanos, en los 


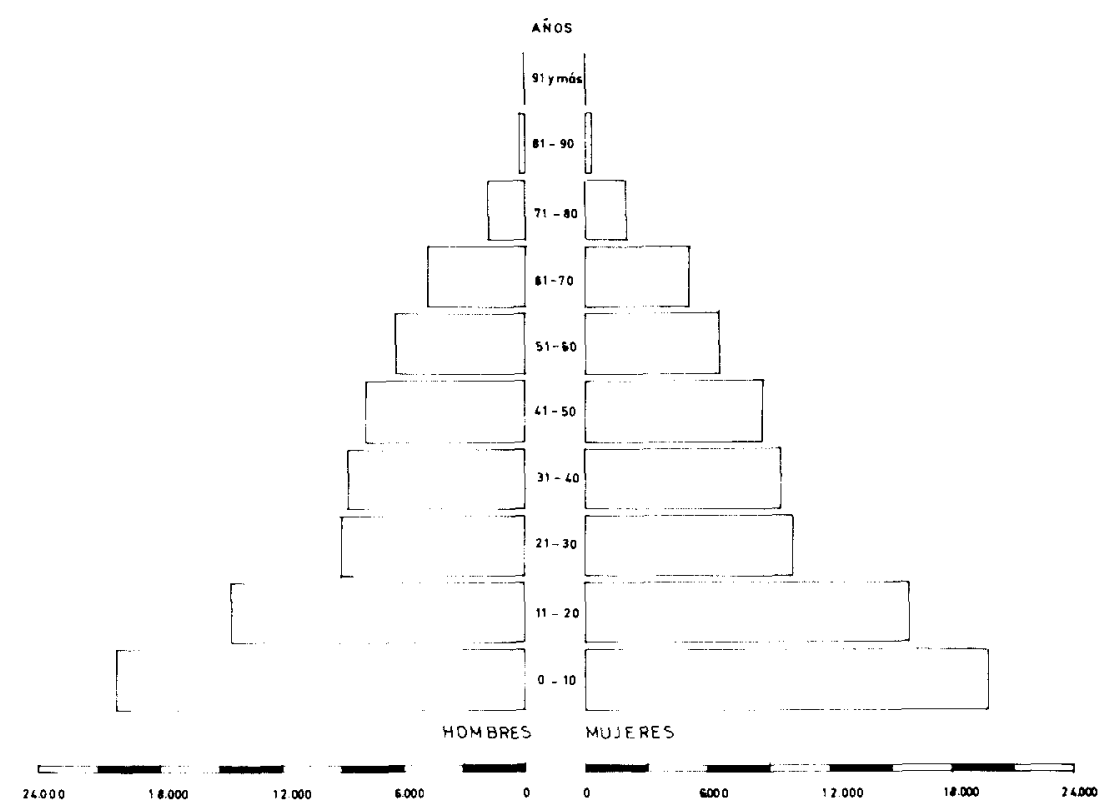

Fig. 7. Composición de la población por edades y sexo. Provincia 1920.

primeros brazos de la pirámide, va igualándose en las edades medias como en los años anteriores estudiados, sólo que las diferencias son menores.

Con la pirámide de 1930, pasamos al estudio de la población por años individuales, lo que supone mayor expresividad en los datos reflejados.

A partir de este año, comienza a cambiar la forma de la pirámide. Es realmente la pirámide de una población joven. Los sectores inferiores que forman la base, no destacan tan netamente como los considerados en años anteriores, sino que forman parte del conjunto, más equilibrado.

Esto puede explicarse por el hecho de que haya disminuido la población infantil o porque la mortalidad en estas edades haya descendido.

En la barra de base, en ambos sectores se observa una muesca en los niños de un año de edad, coincidiendo con la crisis económica de 1929, que tuvo repercusiones en todos los campos. Algo semejante pero 


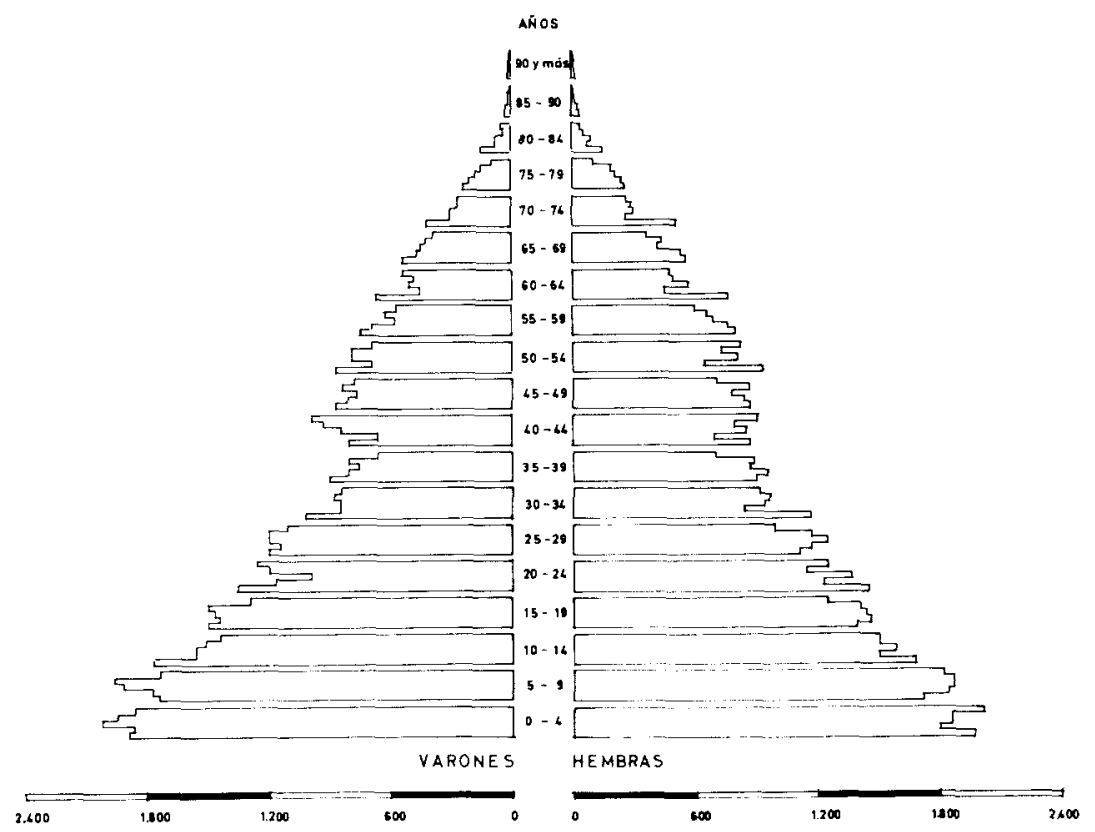

Fig. 8. Composición de la población por edades y sexo. Provincia 1930.

más marcado, se observa en las edades de 10-14 que corresponden a los niños recien nacidos o de corta edad en 1918, año de la terrible pandemia gripal ya señalada, que tantas bajas costó. La entalladura de la pirámide entre los 30 y los 40 años, podría tener parte la misma explicación, en ese caso se trataria, de varones y mujeres que en el año 18 tendrían 20 años, y por tanto en el año 30, estarían en el 32 y de ahí en adelante, pero lo más probable es que el hecho se deba fundamentalmente a los movimientos migratorios, teniendo en cuenta también que la entalladura es mayor en el brazo masculino que en el femenino.

Por otra parte, el estrechamiento superior de la pirámide, no comien$z a$ tan pronto como en 1900,1910 y 1920. La vida se va alargando y no hay cortes bruscos en los brazos de la vejez. Llegan a edades avanzadas mayor número de hombres y de mujeres.

La forma de la pirámide de 1940 , es muy irregular en relación a todas las anteriores. Tiene una forma trebolada, mucho más marcada en el sector masculino, con entrantes profundos que se corresponden con los 20 y los 45 años de edad. La base es bastante más estrecha que los 
brazos superiores. La población de uno a cuatro años ha decrecido notablemente, aumentando bastante a partir de los cinco años.

La huella de la guerra del 36 , recientemente acabada, se nota palpablemente en el descenso de nacimientos correspondientes a esos años, sobre todo 1937,38 y 39 que suponen una muesca notable en el escalón de base de forma excepcionalmente irregular, lo mismo que toda la pirámide. Hay un aumento ligero de los cinco a los 15. El grupo de edades de los 20 a los 30 años da un bajón enorme principalmente en la población masculina debido a las bajas de guerra. Estos brazos corresponden a hombres en edad militar e incluso voluntarios que se alistaron antes de cumplir la edad reglamentaria.

La población adulta sufrió igualmente las consecuencias de la guerra de los 44 a los 54 años, se marca la hendidura del tercer lóbulo del trébol que semeja esta pirámide. La población acusa un fuerte desnivel demográfico, ya que a este potencial que ha bajado efectivamente, habria que añadir la que naturalmente debía haber crecido.

La pirámide provincial de 1950, está elaborada con datos que difieren de todos los anteriores. Es poco expresiva porque aparte de formar los brazos de 10 en 10 años a partir del $2 .^{\circ}$ no alcanza en total más que a los 65 años.

Destacan en ella una base raquítica, que corresponde a los nacidos en el 45 más o menos, y que viene a ser en longitud como los de edad avanzada de 55 años en adelante. Los brazos de mayor longitud son los de 15 a 25 años, tanto varones como mujeres, quedando englobados aquí, tanto los años de baja natalidad correspondientes a la guerra civil, como los de recuperación después del conflicto. El contraste que ofrece en estas edades con la pirámide anterior, es parcial, ya que la muesca importante en la de 1930 se iniciaba en el escaño de los 20 años, y aquí en el de 25, con todo, la criba de la guerra en estas edades fue enorme y se dejará sentir en 1950, pero en un escaño más alto.

De 25 a 55 años apenas existen diferencias en la longitud de los brazos. La silueta de la pirámide es la clásica de una población vieja, en regresión. La baja natalidad no asegura un número suficiente de elemento joven que vitalice la población activa.

Realmente, no existe un corte marcado entre las edades adultas y los ancianos, bien sea porque el trazado de la pirámide lo condiciona por falta de expresividad y de detalle sobre todo en los últimos peldaños, o porque las consecuencias de la guerra afectaran casi con la misma intensidad que a la gente joven, a las personas de edad media, de 40 años 


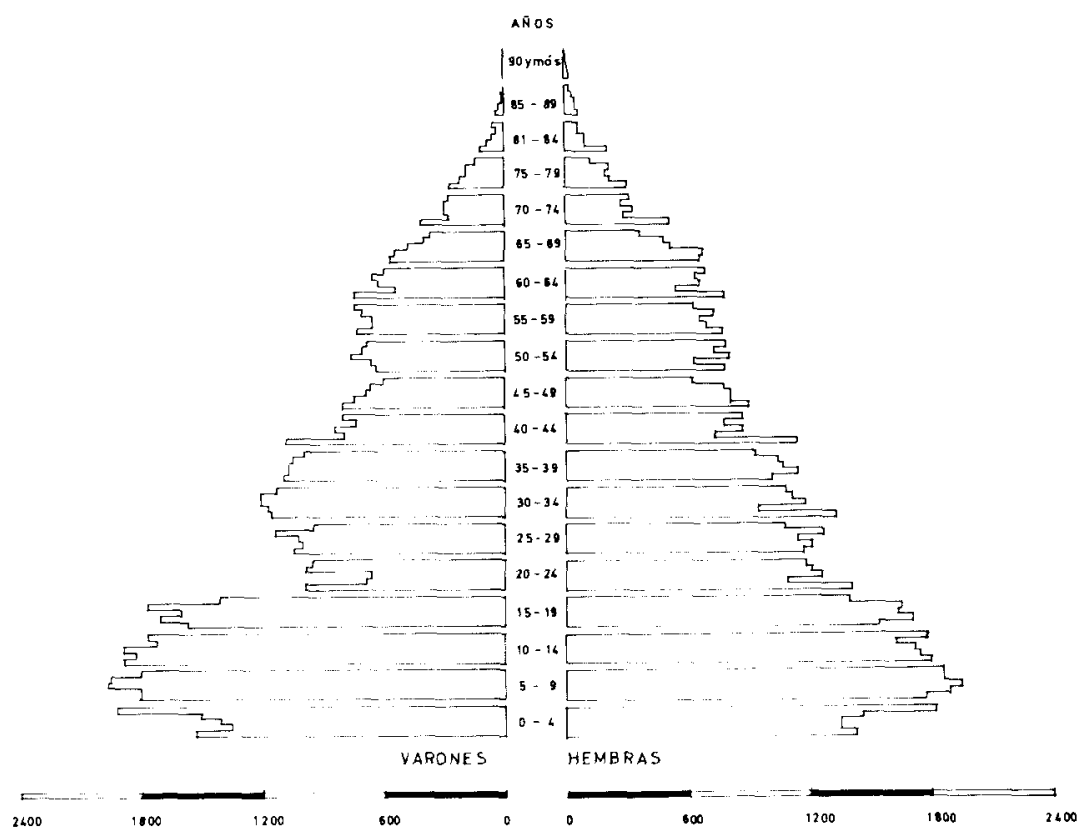

Fig. 9. Composición de la población por edades y sexo. Provincia 1940.

en adelante, lo que hace que los brazos de edad de 55-65 años sean más estrechos que los de 65 en adelante.

La pirámide de 1980, acusa un envejecimiento gradual, que se observa en la longitud muy igualada de los brazos masculino y femenino, tanto en la base, que indica una paralización o un retroceso de nacimientos, como en las edades medias.

Es dificil establecer una comparación entre la pirámide inmediatamente anterior, 1950 y la del 60, que estamos comentando, por el diferente método seguido en la elaboración de los censos. El de 1950, de diez en diez años, resulta inexpresivo en relación con este, año por año, así que comparándola con la de 1940 , se observa que los primeros brazos que forma la base, tienen menor longitud, luego la natalidad ha descendido bastante en proporción, pasando de 1.507 en 1940 a 1.263 en 1960 las cifras correspondientes a los niños de tres años de edad y de 1.450 a 1.112 la de los niños en igual edad. Las diferencias se agudizan de año en año hasta alcanzar el peldaño de los 20 en que más o menos se equiparan, así pasamos de 18.893 y 19.546 para hombres y mujeres respectivamente de 0 a 10 años, en 1940 , a 14.540 y 14.221 en 1960 . 


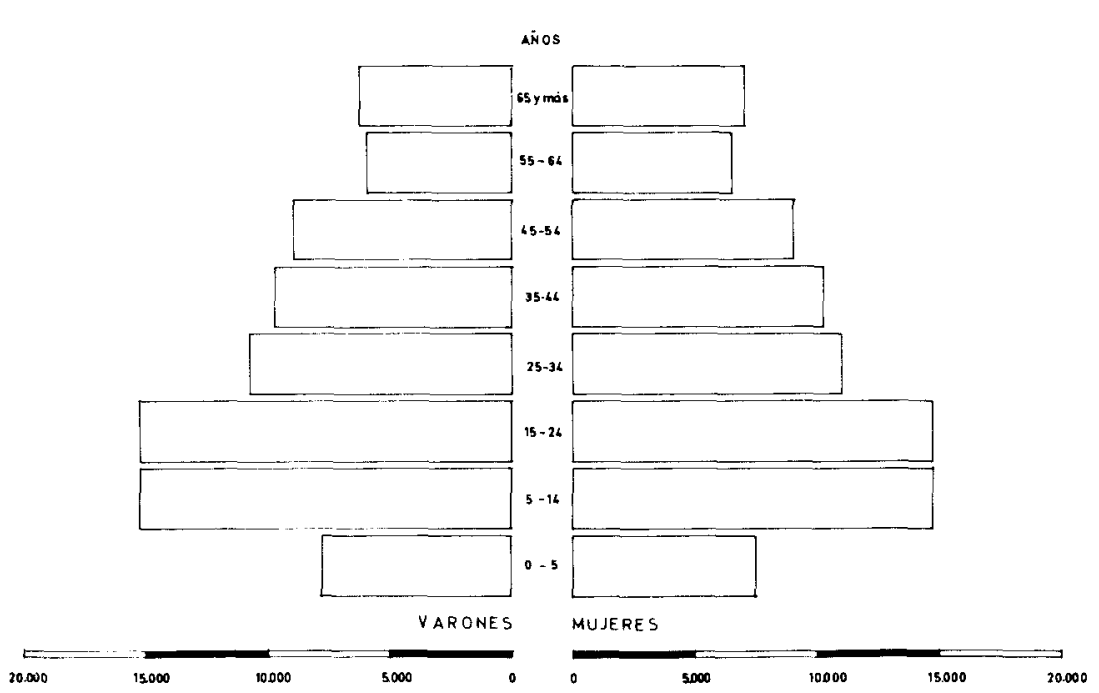

Fig. 10. Composición de la población por edades y sexo. Provincia 1950.

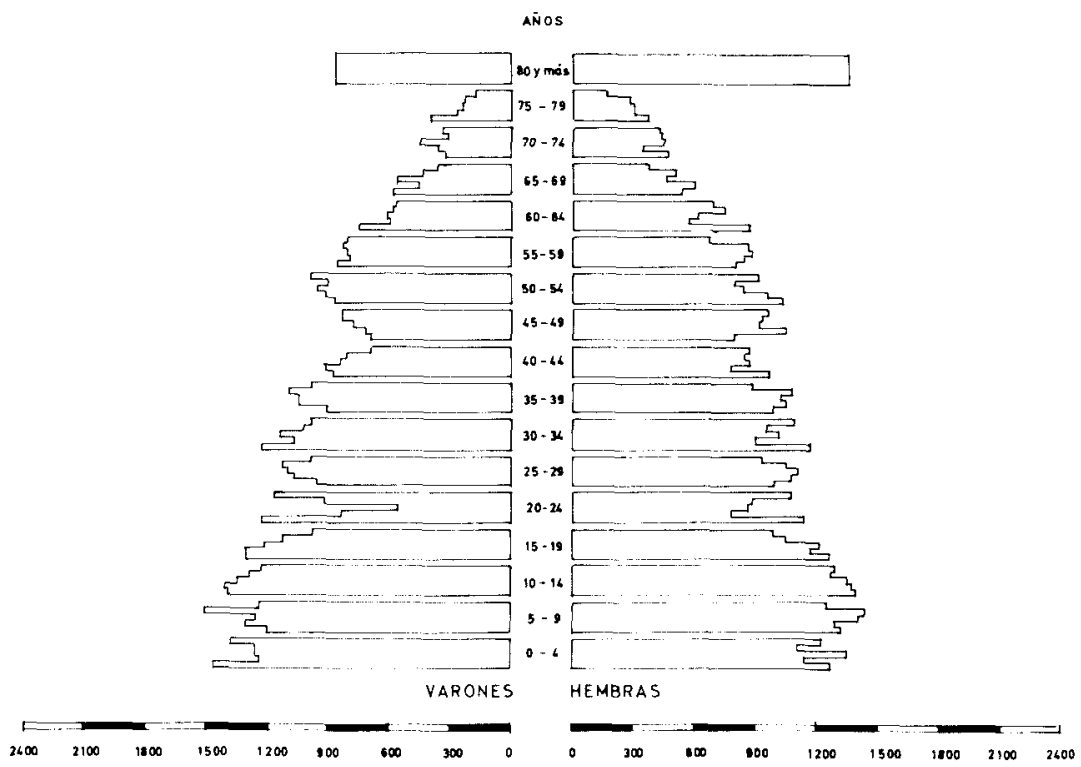

Fig. 11. Composición de la población por edades y sexo. Provincia 1960. 
Este saldo negativo de 4.000 personas de ambos sexos en 20 años, se mantiene en los dos brazos inmediatamente superiores, el $3 .^{\circ}$ y $4 .^{\circ}$ de la pirámide a partir de la base, en que los efectivos masculino y femenino pasan de 16.276 y 16.329 en 1940 a 12.472 y 12.120 en 1960 en las edades de 11 a 20 años, lo que supone envejecimiento enorme de la población. Se observan dos muescas semejantes a la pirámide en 1940, señalizadas en los 20 y los 40 años.

La pirámide coincide con la regresión de nacimientos en los años de la guerra. Los entrantes que presenta el brazo de la pirámide, en ambos sectores, en las edades de 21, 22 y 33 años, corresponden con los niños que deberian haber nacido en 1933, 1938 y 1987.

La segunda muesca de los 42 a los 60 más o menos la integran los supervivientes de la guerra. Son los hombres de 18 a 20 o veintitantos años que formaron filas en la contienda.

Sea por estas causas fundamentales y por las menos importantes de la emigración, acelerada en esta década de modo general en el país, lo cierto es que no existen diferencias notables entre los primeros brazos y los de la edad senil.

Es una población en retroceso, con abundancia del sector adulto de edad media y senil. El censo de este año, ofrece la particularidad de englobar los datos a partir de los 80 años, sin pormenorizar año por año.

La pirámide de la población de la provincia de Soria en 1970 presenta unos rasgos que demuestran su evolución hacia la configuración de un tipo de población de tipo medio.

Se observa en general una gran igualdad en los brazos de la pirámide en los distintos tramos, tanto en los correspondientes a varones como a hembras, lo cual estaría relacionado con el descenso general de la natalidad y el crecimiento en el número de personas que llegan a la vejez.

A pesar de que el primer brazo sólo recoge los datos de cinco años, y no los de 10 como los demás, aún multiplicándolo por dos, reflejaria el importante descenso de la población menor de cinco años con respecto a la pirámide de 1960, y cuya explicación habría que buscar tanto en la disminución de las tasas de natalidad, como en la emigración a otros lugares producido en los últimos años del "boom" de los sesenta.

Esta emigración de la que hablamos vendría reafirmada en la fuerte entalladura correspondiente al grupo de 25 a 34 años que correspondería, precisamente, con parte del sector de mujeres de 15 a 24 años, al 


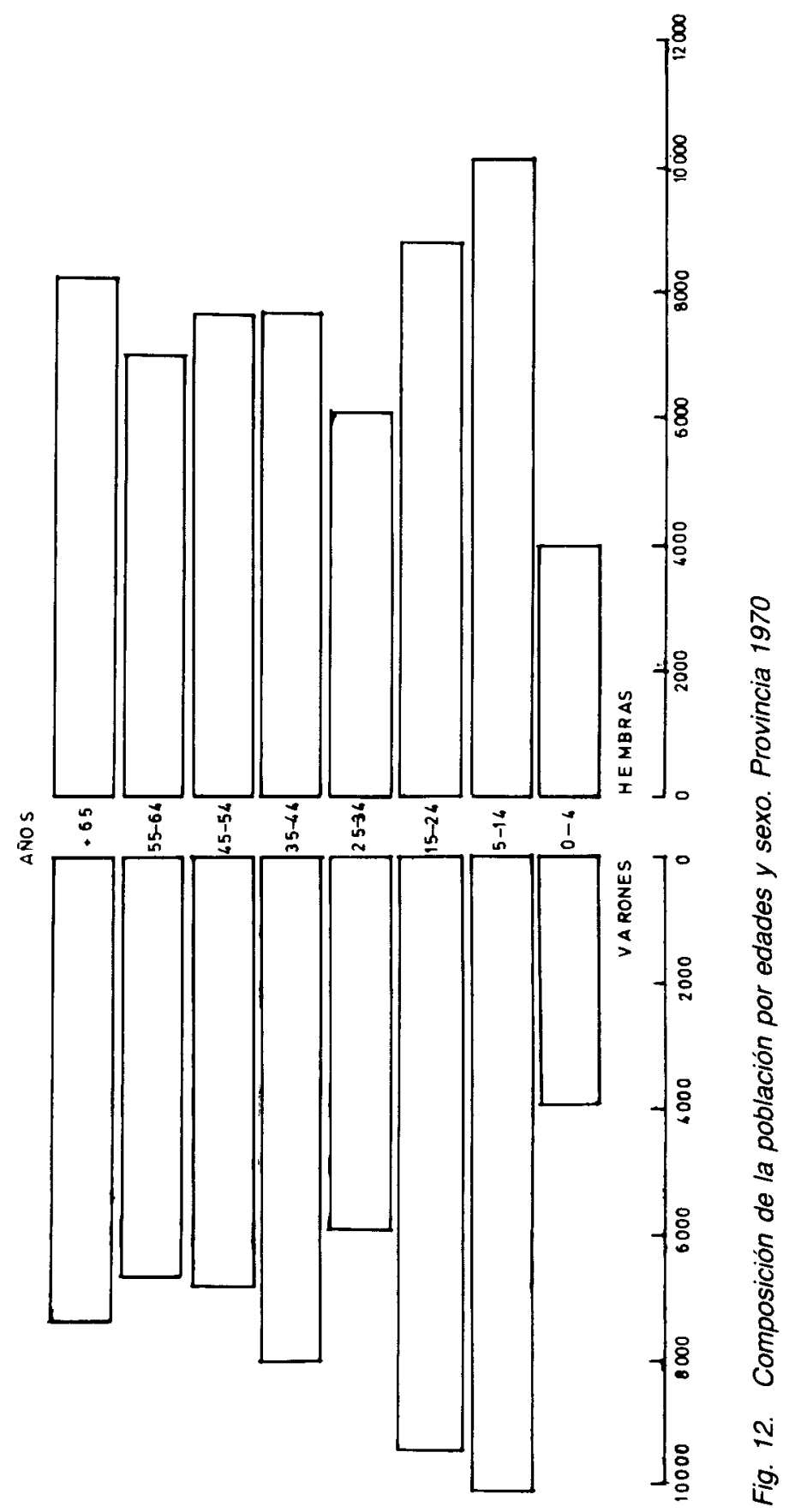




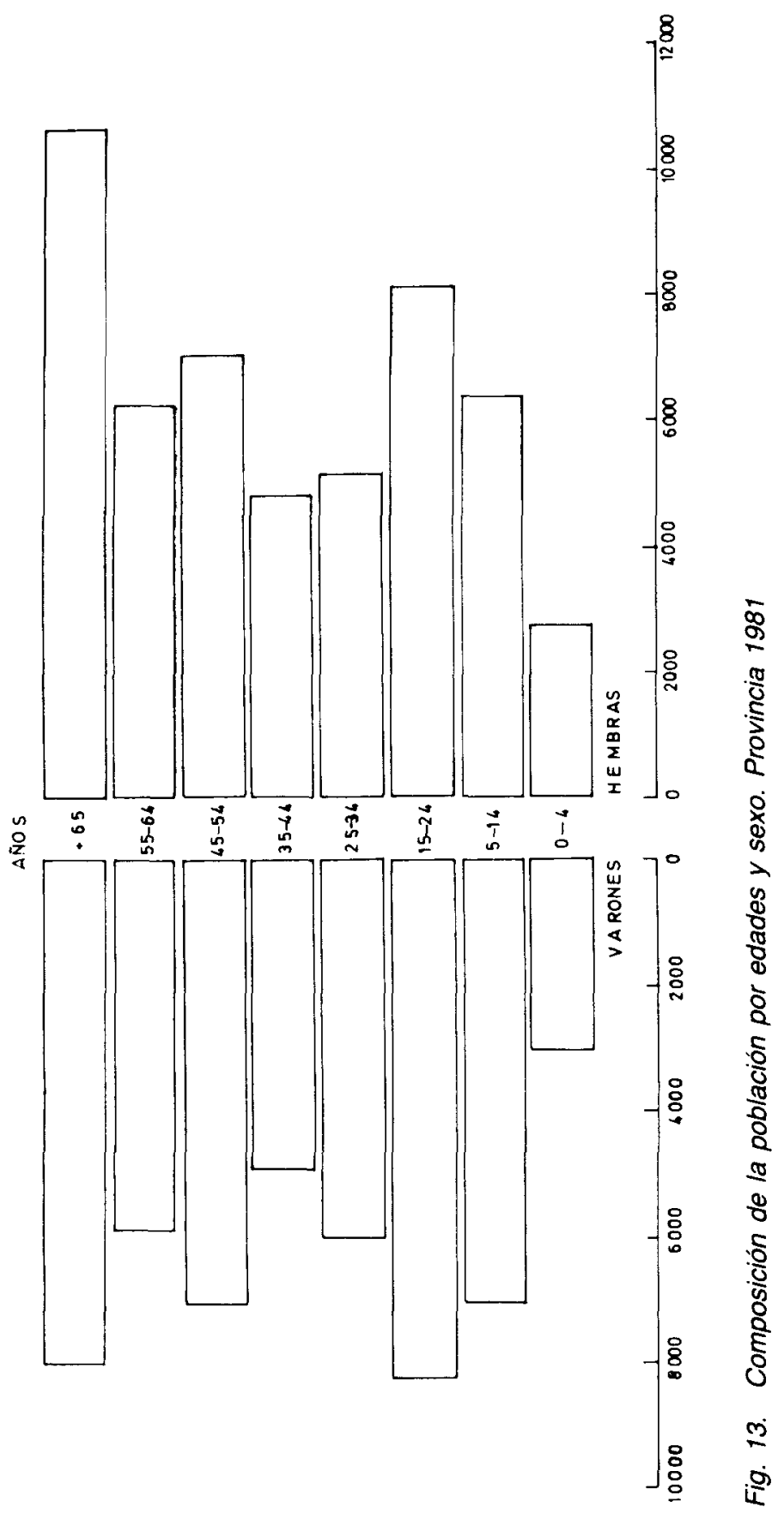


núcleo de la emigración soriana; son pues, hombres y mujeres jóvenes que marchan a otros lugares en busca de mejores horizontes de todo tipo. Sin embargo, en este grupo de 25 a 34 años sería necesario descontar el hueco producido por el descenso de nacimientos del período de la guerra civil, que tendria en 1970 entre 25 y 34 años de edad.

Finalmente, comentar que la pirámide de población de la provincia de Soria presenta una gran estabilidad a partir del tramo comprendido entre los 35 y 44 años, que corresponde a un envejecimiento general de la población, como consecuencia de las mejores condiciones alimentarias, higiénicas, sanitarias, etc.

La pirámide de la población de la provincia de Soria de 1981 presenta la misma tónica, quizás un poco más marcada, del proceso de disminución de la natalidad y aumento de la población adulta y senil. Las mejores condiciones higienicas y sanitarias del país en general, y de Soria en particular explicarían este elevado porcentaje de población tanto mayor de 65 años, como mayor de 45 años. Por otra parte, este tipo de población tiende a permanecer en sus lugares de residencia, tanto por un mayor apego a la tierra, como por la carencia de oportunidades para las personas de estas edades.

Como reflejo de la entalladura del grupo de 25 a 34 años de la pirámide de 1970, se marca un profundo entrante en el grupo de 35 a 44 años en ésta de 1981, y cuya razón de ser la hemos explicado anteriormente.

También en 1981 se observa otro entrante en el grupo de 25 a 34 años cuya explicación hay que buscarla en la emigración de los jóvenes de estas edades, sin embargo se observa un descenso de la emigración a causa de las menores expectativas derivadas de la crisis de los setenta, a pesar de lo cual sigue siendo importante el grupo emigrante.

Las tasas de natalidad siguen cayendo tanto por la continuidad de la tendencia marcada a lo largo del siglo, como por las mismas dificultades económicas.

\section{Pirámides de población de la capital}

Las pirámides de 1900,1910 y 1920 para la capital siguen el mismo sistema de elaboración que para la provincia. Los datos tomados de los censos, están agrupados de 10 en 10 años. 
En los tres años mencionados, a partir de principios de siglo, se observa cierto equilibrio entre los sectores masculino y femenino que va aumentando gradualmente a favor del segundo. Decididamente, hay más mujeres que hombres, sobre todo en edades medias. La base de la pirámide es parecida en las tres que consideramos, marcándose incluso un retroceso a partir de 1900 , más apreciable en el sector femenino, que irá ganando efectivos, suavizando el escalón de los 21-30 en las edades medias que llegarán a uniformizarse en la pirámide de 1920, sobre todo en el sector masculino, donde prácticamente se conformará un tronco sin aristas marcadas, de los 21 a los 51 años de edad, sobresaliendo de una base irregular, no muy amplia, con un segundo escalón más desarrollado, como ocurre en la de 1910, base de todas formas insuficiente que denota el estacionamiento de la población, incluso el retroceso general, aunque destaque más en los varones. Efectivamente a partir de los 20 años, el sector masculino desciende casi en vertical, sin cambio notable entre los jóvenes y los de edad madura, sobre todo en la última pirámide como ya hemos señalado anteriormente.

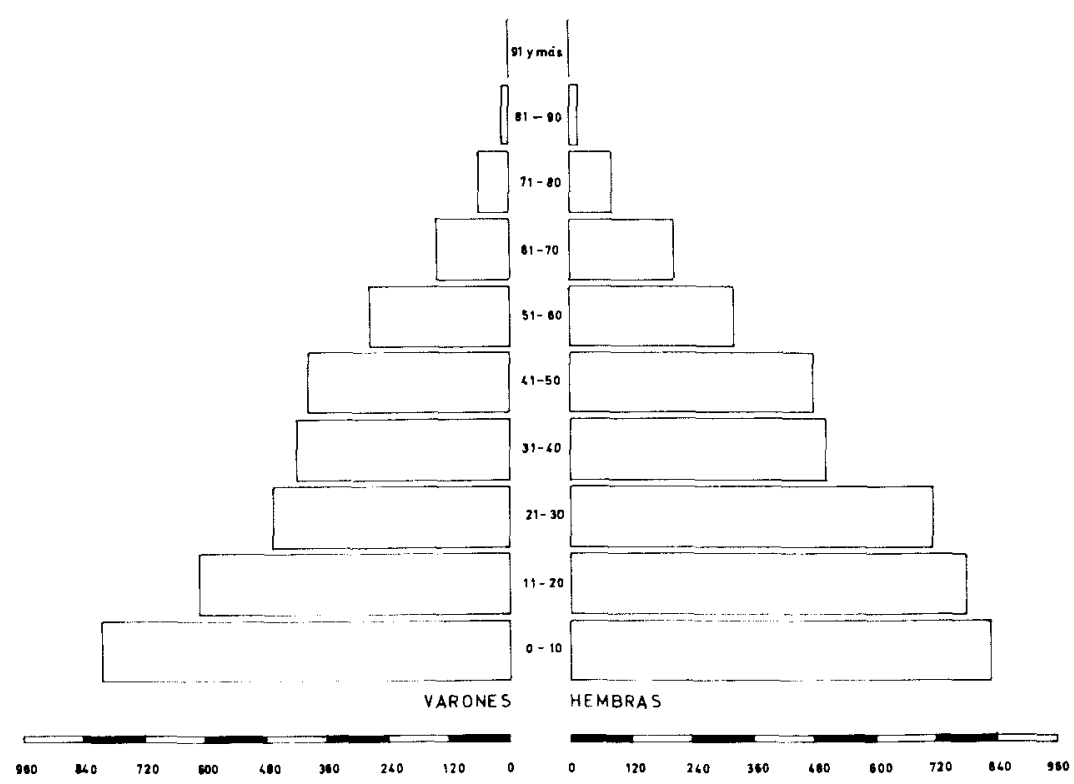

Fig. 14. Composición de la población por edades y sexo. Capital 1900. 


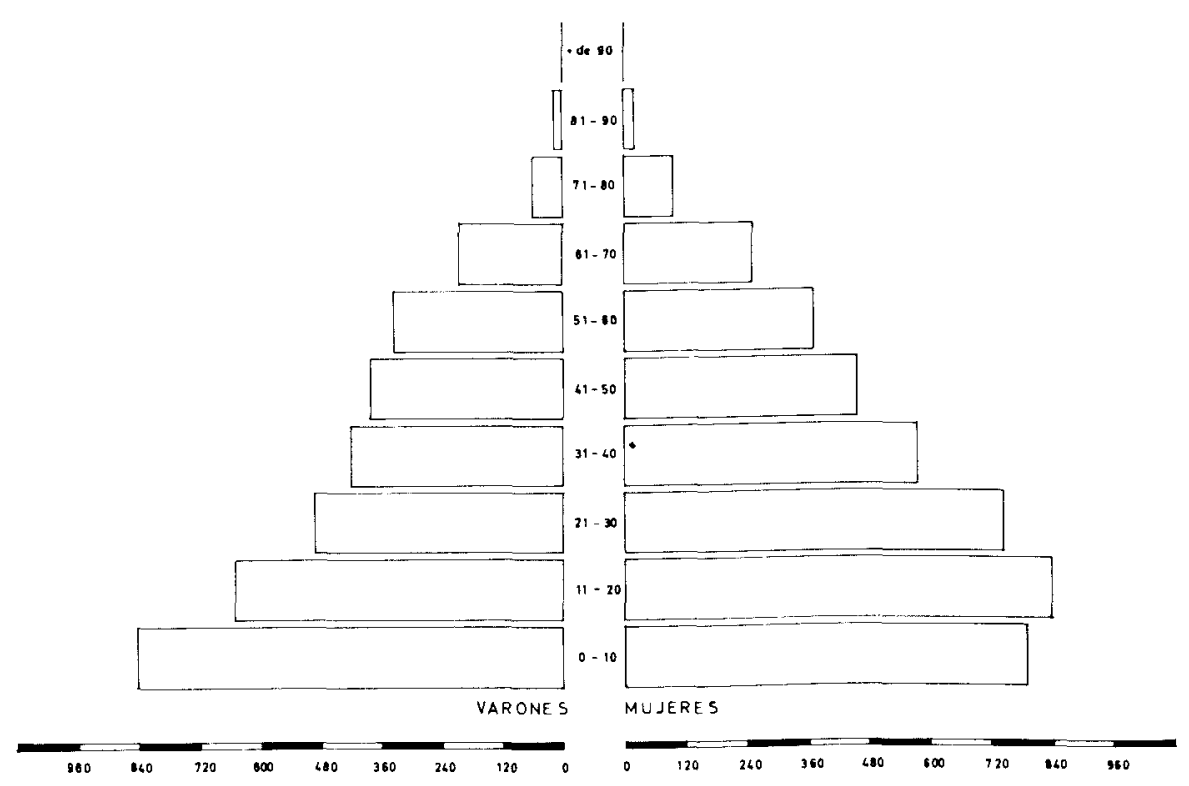

Fig. 15. Composición de la población por edades y sexo. Capital 1910.

Este hecho aquí más marcado puede considerarse sin embargo, común en las tres pirámides, y es debido principalmente al carácter migratorio de la población, a la edad reglamentaria para la guarnición militar coincidente con esas edades en el sector masculino. Por el contrario, los efectivos femeninos aumentan en general a partir del segundo brazo en edades que oscilan en los primeros años y con las de servicio doméstico en los últimos, este dato sobre todo puede ser explicativo, ya que en esas edades y a principios de siglo la mujer ejecutaba un trabajo no cualificado, y servir en la capital era la salida común para la chica de pueblo.

Otro rasgo que se va generalizando y adquiere más importancia de año en año, es la prolongación del término medio de la vida que va engrosando los últimos brazos de la pirámide haciendo cada vez más inestable el equilibrio de una población estancada asentada sobre una base no muy amplia. 


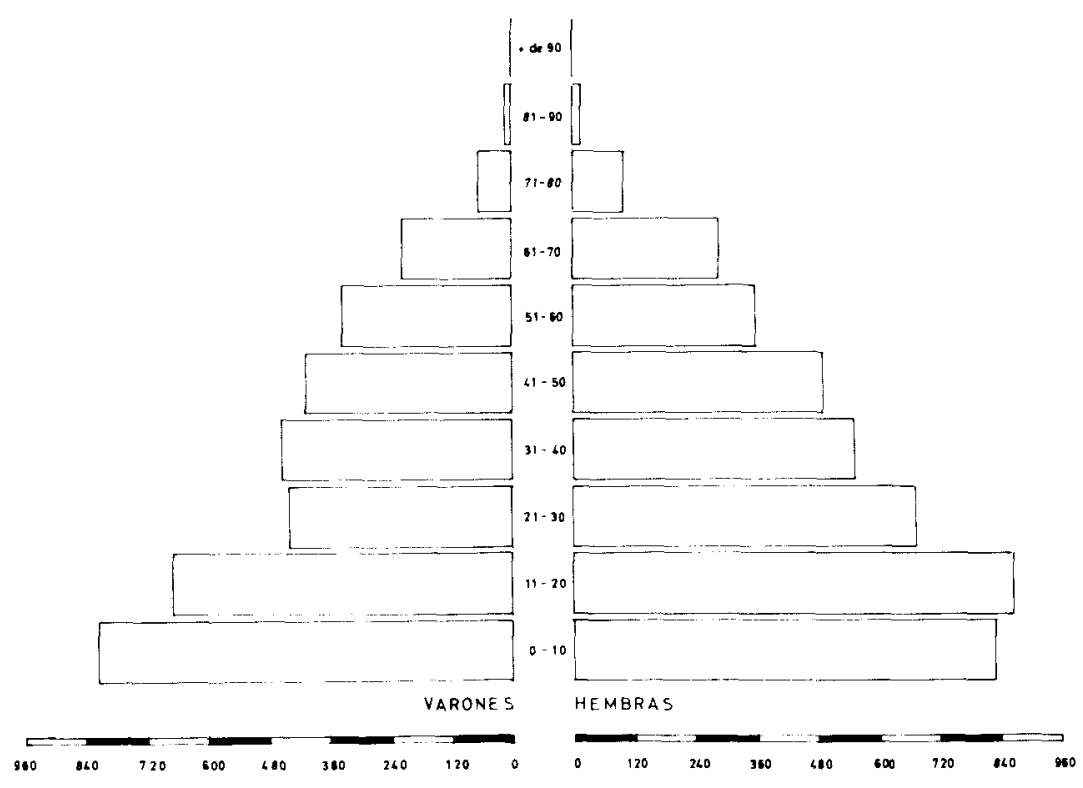

Fig. 16. Composición de la población por edades y sexo. Capital 1920.

La pirámide de la capital en 1930 , ofrece la particularidad respecto a la del mismo año provincial, del mayor desarrollo de los brazos de edades jóvenes comprendidas entre los 15 y los 30 años, sobre todo en el sector femenino donde se alcanza la máxima de la capital con unos efectivos de 146 jóvenes de 17 años, seguidas por las de 20 años, que alcanzan la cifra de 136.

Coinciden, como ya hemos comentado en las pirámides anteriores, con la fuga del pueblo en busca de un empleo en la ciudad, siendo el más generalizado el de servicio doméstico en la mujer y el de peón o subalterno en el hombre. En contraposición a lo anterior, estas máximas señaladas en el sector femenino son mínimas en el masculino ya que coinciden con la edad de alistamiento voluntario y obligatorio para cumplir el servicio militar. Así en la capital de Soria hay tan solo 76 muchachos de 17 años en el año que comentamos y 46 de 21 años, cuando la mujer de esta edad alcanza la cifra de 106.

Los 18 y los 25 años, son para los hombres las edades que alcanzan mayor número de efectivos en la capital, como lo habian sido los 17 y los 20 para las mujeres y por el mismo motivo: la busca de empleo. 


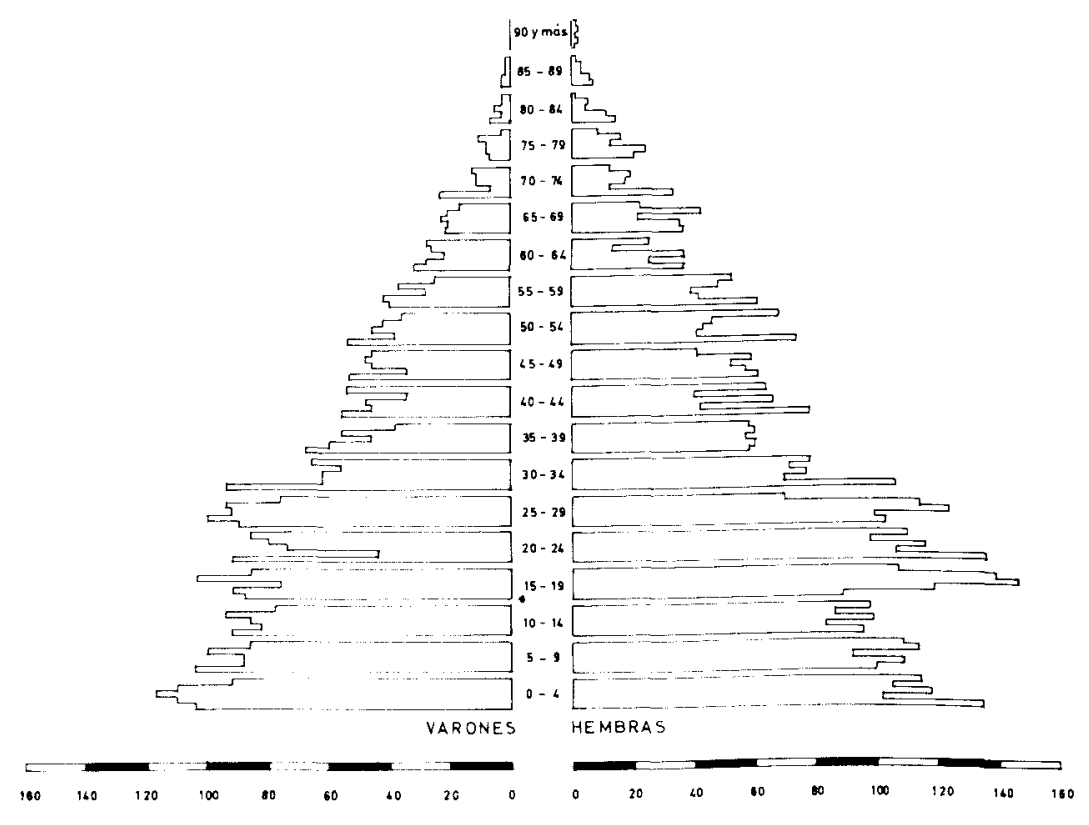

Fig. 17. Composición de la población por edades y sexo. Capital 1930.

Como ya hicimos con la provincia, señalaremos aqui las dos entalladuras que sufre la pirámide en los brazos de 10 a 14 años de edad y de 30 a 40 en ambos sectores de población, coincidiendo en el primer caso con los niños recién nacidos o muy pequeños en 1918, año de la pandemia gripal y en el segundo con los que en esa fecha tenian veinte años.

En conjunto, la pirámide es bastante armónica en su trazado, condensando los máximos de población en edad de producir, el aumento de efectivo en edad madura y senil, sobre todo en el sector femenino.

El de 1940 es un censo con un significado especial por ser el que siguió inmediatamente a la guerra civil española, hecho que queda reflejado en la estructura por edades de la población, en la base raquítica que forma el primer brazo de la pirámide con edades comprendidas entre cero y cuatro años correspondientes a los escasos nacimientos de 1936 , 1937, 1938 y 1939, en el brusco entrante que experimentó el brazo masculino a partir de los veintiún años y que coincide sin duda con el reclu- 
tamiento de tropas ordinario y con las bajas del frente, más acusados en el grupo de voluntarios por ser muchachos inexpertos, de corta edad.

Prácticamente podiamos dividir en dos franjas paralelas, la pirámide de Soria capital en el años 40.

La primera se daría desde la base desdentada hasta los 41 años de edad. La segunda, desde entonces hasta los 65 años, quedando fuera de juego el pináculo con edades seniles, desde los 65 años hasta los 90 y más años, sector muy desarrollado por cierto, en relación con el que arroja la pirámide provincial en el mismo año.

La diferencia entre ambas franjas, trazando más o menos una línea media rectilínea por los puntos más sobresalientes, seria en el sector masculino la que va de 125 a 50 y un poco menos para el femenino, más desarrollado, así el desnivel en este sector sería de 125 a 75, uniformando las dos franjas.

En conjunto, el potencial de población está compensado aunque a la larga, la inestabilidad de la base tenga efectos retardados.

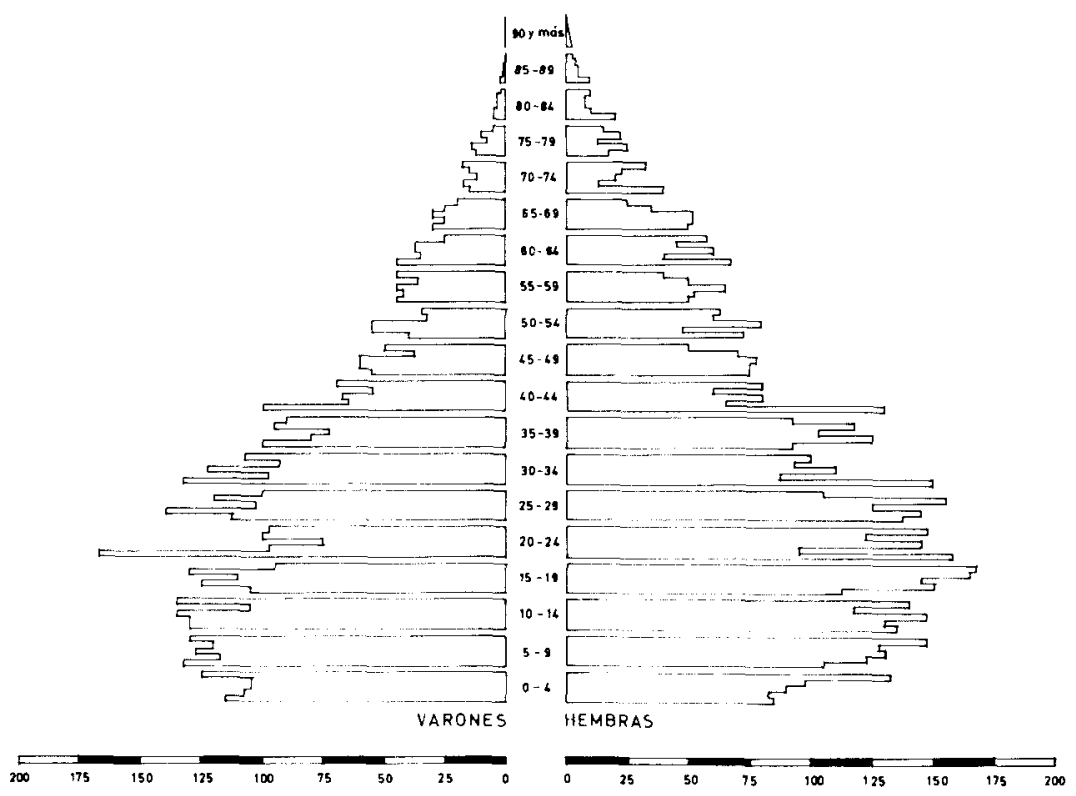

Fig. 18. Composición de la población por edades y sexo. Capital 1940. 
Los datos de 1950 están agrupados de distinta forma que el resto de las pirámides, como ya dijimos antes, asi que esta que vamos a comentar no ofrece similitudes más que con la provincial de este mismo año.

Comparando ambas observamos una simetría casi perfecta entre los sectores masculino y femenino, de la provincial, cosa que no se mantiene en la capital. Sobre una base raquítica, se asientan dos brazos desiguales que conforman una figura casi romboidal de la pirámide. El primer brazo con edades de 5-14 años, poco más desarrollado en el sector masculino, con un total de 1.432 varones sobre 1.206 mujeres, precede al eje máximo situado en los 15-24 años de edad que corresponde a los niños nacidos en años inmediatamente anteriores a 1936, a partir de este momento, el sector femenino irá ganando terreno, haciéndose más notables las diferencias conforme nos acercamos a los brazos superiores de la pirámide. Así contaremos 661 varones y 949 mujeres de 45-54 años de edad y con 20 años más, es decir en edades de 65 en adelante encontramos unos efectivos femeninos de 859 mujeres sobre 350 varones. Es evidente que la mujer vive más que el hombre y que este hecho se acentúa más en la capital que en el resto de la provincia, ya sea por el tipo de trabajo, régimen familiar o mejores condiciones de vida, de tal forma que la descompensación entre los dos sectores es evidente.

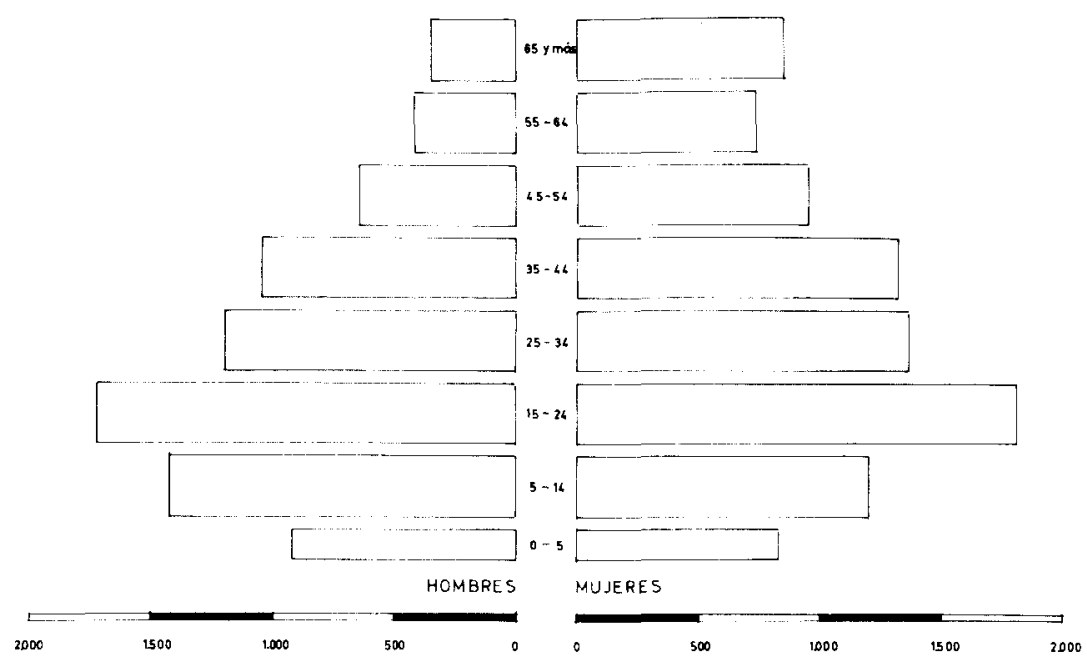

Fig. 19. Composición de la población por edades y sexo. Capital 1950. 
La década de los años 1950-1960 quedará marcada por el signo del éxodo del campo a la ciudad. La despoblación del área rural y la superpoblación de la ciudad que aparece como un oasis, se convertirá en un fenómeno general del que Soria no podría ser una excepción. La base de la pirámide es amplia, 240 varones y 194 mujeres nacidos en este año y las cifras se repiten aunque no tan elevadas en años sucesivos, 10 que demuestra que el índice de natalidad y nupcialidad de la capital corresponde al de una población joven en vías de expansión. Como ya hemos comentado con anteriores ocasiones, resultan casi fijos los indicativos de aumento o disminución en una determinada edad, así, los 16 y 17 años en la mujer dan una barra relativamente amplia dentro del brazo de los 15-19 años de edad y coinciden con la llegada a la capital de las chicas en edad de servir, al menos esa era hasta entonces la principal ocupación, pero de ahora en adelante, se ampliará el plantel de posibles trabajos a realizar, conforme se vaya incorporando la mujer a la vida social. La edad militar en los hombres determina siempre una pequeña muesca en la pirámide de que se trate, aunque la capital acuse menos la pérdida que el total provincial.

Los años de la guerra, se vienen arrastrando a distintos niveles de edad, conforme pasan los años, y aquí coinciden con la entalladura del brazo de los 20-24 años más acusado en el sector masculino que

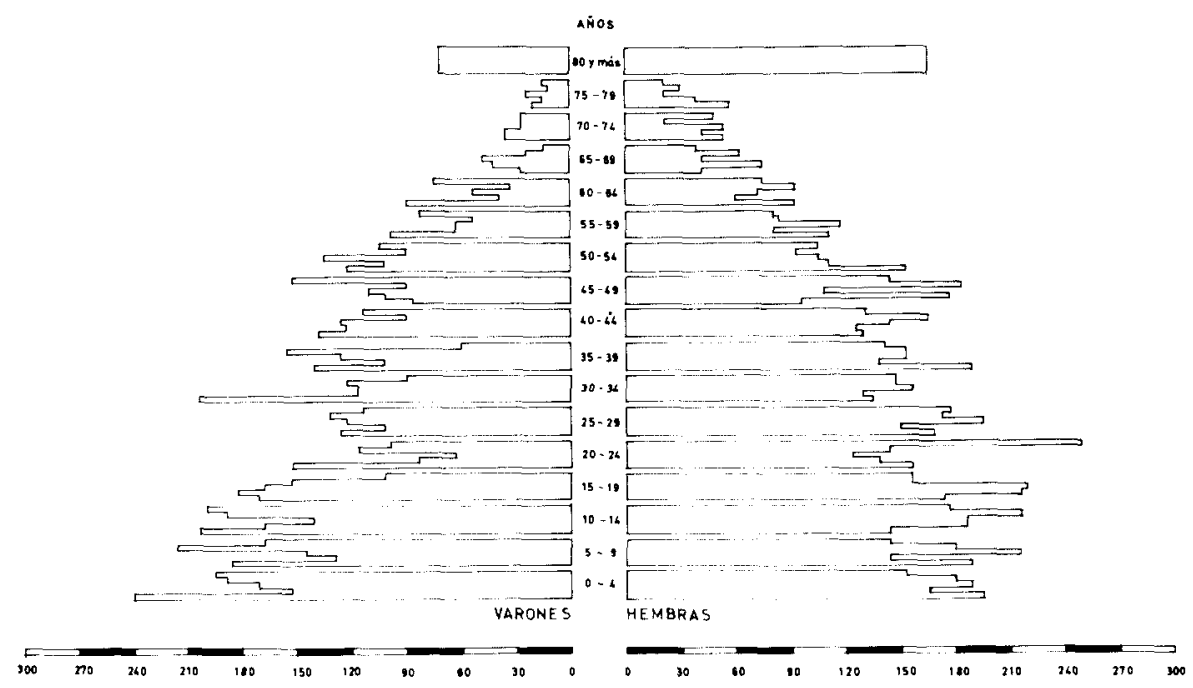

Fig. 20. Composición de la población por edades y sexo. Capital 1960. 
corresponden a los nacidos en los años de conflicto. Por lo demás, la pirámide está bastante equilibrada con potencial de población joven, compensada en los dos sectores, masculino y femenino, con algunos niveles excepcionales como el de los 24 años en las mujeres y el de los 30 en los varones aun dan en el primer caso un total de 254 sobre 98 varones de la misma edad, y en el segundo 204 a favor del sector masculino, sobre 135 en las mujeres. Ambos fenómenos pueden deberse a la emigración ya comentada, que acoge siempre a distinta edad a uno y otro sexo.

El índice medio de vida que va aumentando en general, se aprecia más en la ciudad, y la barra final distorsionada en el sector femenino, es indicativo de los progresos de la medicina en todos los campos.

La pirámide de 1970 sigue presentando un tipo de población de carácter medio, aún tiene una amplia base, en torno a las 2.000 personas por cada sexo, es decir, mantiene aún una alta natalidad que, sin embargo comienza a equilibrarse y a descender, como se vería si multiplicaramos por dos el grupo de 0 a cuatro años.

Al igual que sucede en la provincia, y a pesar de las mayores posibilidades que ofrece la ciudad, se observa el gran corte correspondiente al grupo comprendido entre los 25 y 34 años, tanto de hombres como de mujeres, que corresponde, como ya hemos explicado a los efectos de la guerra como a la emigración. Así pues, son los jóvenes de 25 a 35 años los que marchan de Soria, pues ésta, a pesar de ofrecer los servicios de una capital, no ofrece los suficientes como para absorver a su población. Emigración de población joven que influirá en la composición de la población de los años posteriores, por cuanto están en los mejores años para procrear, y tendrán descendencia que ya no nacerá en Soria.

A partir de este brazo, la pirámide vuelve a unos valores que podríamos considerar como normales dado su tipo medio, con un descenso progresivo de los componentes de los demás grupos de edades, en el que sólo sería reseñable el aumento en el último brazo, en el sector femenino, que, como ya hemos explicado anteriormente, reflejaria la mayor resistencia de las mujeres frente a los hombres.

La composición de la población de 1981 parece indicar una estabilización en el número de nacimientos en la capital, frente al retroceso de la provincia; estabilización que habría que explicar por las mayores posibilidades que ofrece la capital y por el tipo de ocupación de sus habitantes. 


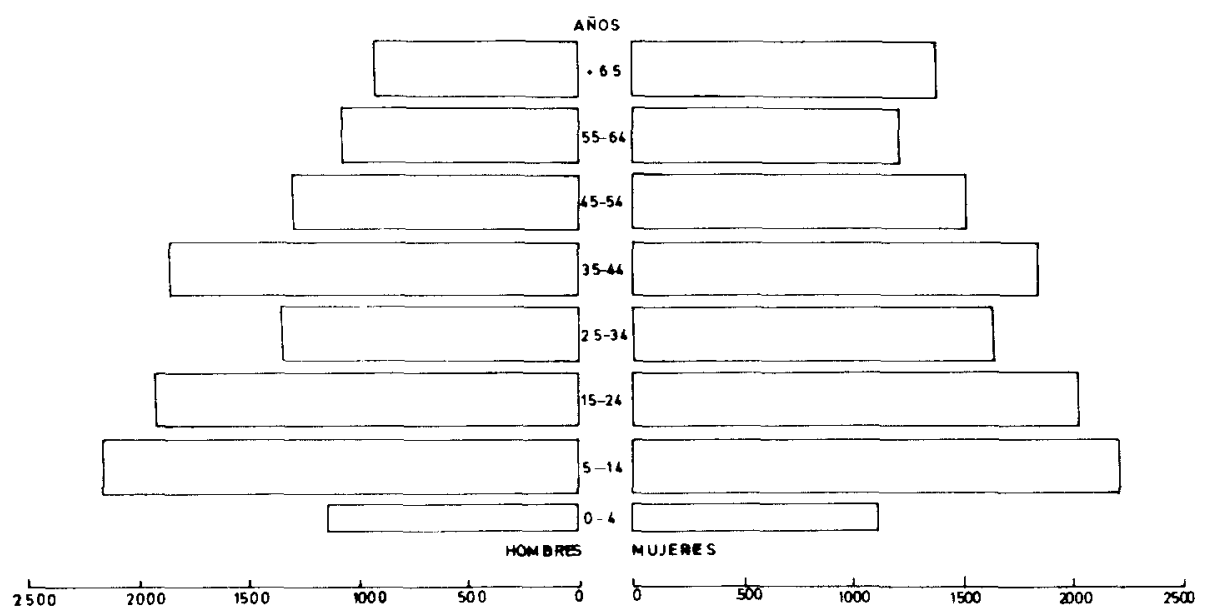

Fig. 21. Composición de la población por edades y sexo. Capital 1970

Continua observándose el entrante correspondiente al grupo comprendido entre los 35 y 44 años que corresponde a similar entrante del grupo de 25 a 34 años de la pirámide de 1970, y que ya explicamos anteriormente.

Asimismo encontramos otro entrante en el grupo de edades comprendido entre 25 y 34 años correspondiente al grupo de emigrantes, jóvenes que marchan de Soria por cuanto, ésta, no ofrece posibilidades a los jóvenes de la capital, lo cual repercutirá inevitablemente en el número de nacimientos de los años posteriores. Pero no es sólo el grupo comprendido entre 25 y 34 años, sino que se observa ya en el grupo anterior la disminución en el número de los varones frente a las hembras, que refleja el inicio, cada vez más temprano de la búsqueda de trabajo por parte de la juventud soriana, una vez que terminan su servicio militar o sus estudios.

Por último, y como ya se ha visto reflejado en datos anteriores, se aprecia la similitud en el número de la población adulta y senil, y un aumento en el grupo de mujeres mayores de 65 años correspondiente a las mayores expectativas de vida de las mujeres respecto a los hombres. 


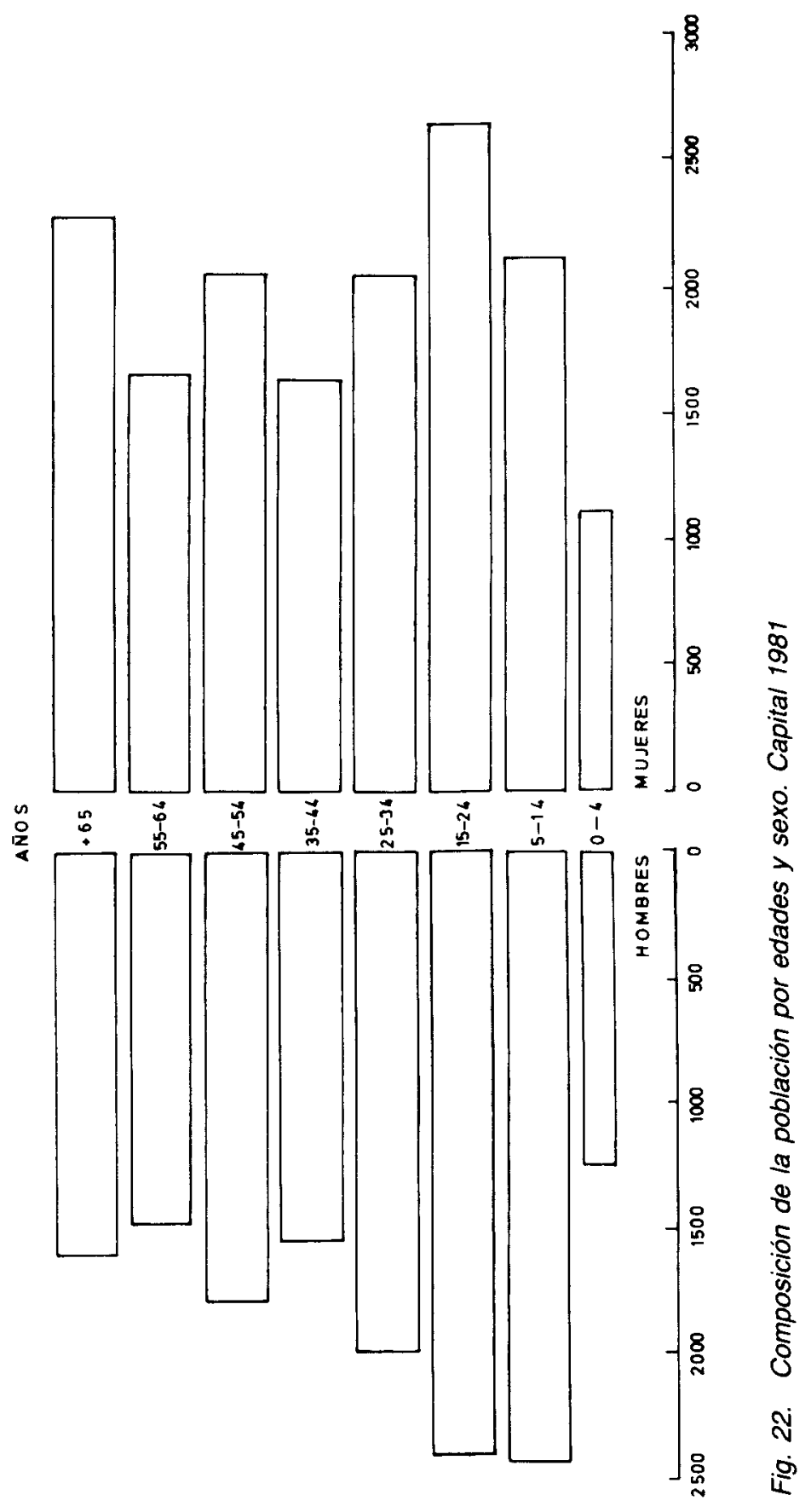




\section{ESTUDIO CUANTITATIVO DE LA POBLACIÓN}

Densidad de población: Evolución y cambio a través del tiempo

Para estudiar el análisis cuantitativo de la población, comentaremos ahora los mapas que expresan su densidad, aumento y disminución en los años: 1900, 1960, 1965 y 1970, considerados los más expresivos ya que pueden reflejarnos fielmente la evolución de la población soriana desde principios de siglo hasta la actualidad más inmediata, pasando por un período general de recuperación después de la guerra civil.

En los mapas que hemos confeccionado distinguimos distinta intensidad de tonos que irá de menor a mayor, según la densidad. Así las zonas más claras, corresponderán a las más despobladas, y las más oscuras a aquellas donde la densidad es mayor.

Según esto, la bajísima densidad provincial se aprecia especialmente en el centro que desde antiguo ha ido disminuyendo paulatinamente pasando de una densidad $11-15$ de 1900 a 1950 , a la de 6-10 en 1960 y finalmente $0-5$ en 1966, hecho que corresponde a los tres primeros intervalos.

Solo el núcleo NW de la provincia que comprende los municipios de Covaleda, Duruelo de la Sierra y la capital, aumenta considerablemente la densidad desde principios hasta mediados de siglo, aumento casi fijo hasta 1965, ya que apenas se observa variación notable.

Así Soria capital, con una densidad de 19,5 en 1900 , que en la escala de valores que hemos elaborado, corresponde a una densidad de 16-20 (valoración media) aumentará a 43,21 en 1950, 52,8 en 1960 y 59,73 en 1965. Es mucho más destacado pues el aumento que se observa en los dos primeros años comentados, que en los de 1960 y 1965.

La existencia de grandes mancomunidades, como la Tierra de Soria, constituida por la capital y 150 pueblos que explotan en común grandes extensiones de pinar y los enclaves administrativos (pertenencias de término municipal dentro de otro) explotados unas veces en el municipio en que se hallan situados, o bien por el que pertenecen. En cualquiera de los dos casos podrían inducirnos a error. Por lo tanto hemos considerado como más conveniente, dejar en blanco estos espacios en el mapa, ya que además son tierras casi deshabitadas las correspondientes a pinares de explotación común y sólo es en el terreno económico en el que habrá que considerarlos. 
Otros núcleos fijados de elevada densidad con respecto al total provincial, destacan a modo de islas. Son los de Burgo de Osma, Arcos de Jalón al Sur y Almarza y Barriomartín en el Norte. Estos municipios con densidades altas, están situados en zonas con un índice de densidad bajo, de forma que las razones de esta intensidad, habrá que buscarlas en las comunicaciones, las funciones administrativas o la economía. Realmente todas ellas coinciden como cabezas o núcleos principales de mercado.

La densidad de Burgo de Osma ha descendido desde 54,2 en 1900, 51,60 en $1950,55,6$ en 1960 a 55,20 en 1965.

Barriomartín, lindante con Almarza da la máxima densidad de la provincia con 104,6 habitantes por kilómetro cuadrado en 1900. Aumentó después de la guerra, en 1950 a 143,41 para descender en el período siguiente a 120,9 en 1960 y 117,85 en 1965 , siguiendo la tónica de despoblamiento general de la provincia.

La densidad de Almarza, casi paralela a la del Burgo de Osma, sigue igualmente en descenso paulatino salvo el ligero aumento del año 1950. Así pasa de 65,1 en 1900 a 65,6 en 1950, para descender a 59 en 1960 y a 51,07 en 1965 .

Finalmente, el cuarto municipio de más elevada densidad, Arcos de Jalón, le corresponde un aumento progresivo en los tres primeros años que comentamos. Densidad 34,6 en $1900,78,46$ en 1950,79 en 1960 para descender a 74,92 en 1965. El aumento espectacular del 1900 a 1950 , se debió a la instalación de depósitos y talleres ferroviarios como centro importante de comunicaciones, actualmente en decadencia.

Salduero y Muriel de la Fuente, son términos municipales muy pequeños que dan densidades completamente irreales. Muriel de la Fuente con una extensión de 3,62 kilómetros cuadrados tenia 170 habitantes en 1965 dando una densidad de $46,96 \mathrm{~h} / \mathrm{km}^{2}$. Y Salduero en el mismo año con 2,48 $\mathrm{km}^{2}$ y 376 habitantes alcanzaba la densidad de $151,61 \mathrm{~h} / \mathrm{km}^{2}$, una de las más altas de la provincia. Por lo tanto, hay que prescindir de estos municipios cuando se mire el mapa.

Soria va a la cabeza entre las provincias de menor densidad de población, seguida de cerca por Guadalajara. La despoblación de la provincia es rápida y progresiva.

Para contrastar con mayor precisión estos datos, señalaremos las provincias con menor densidad de población, situadas muy por debajo de la media nacional. 


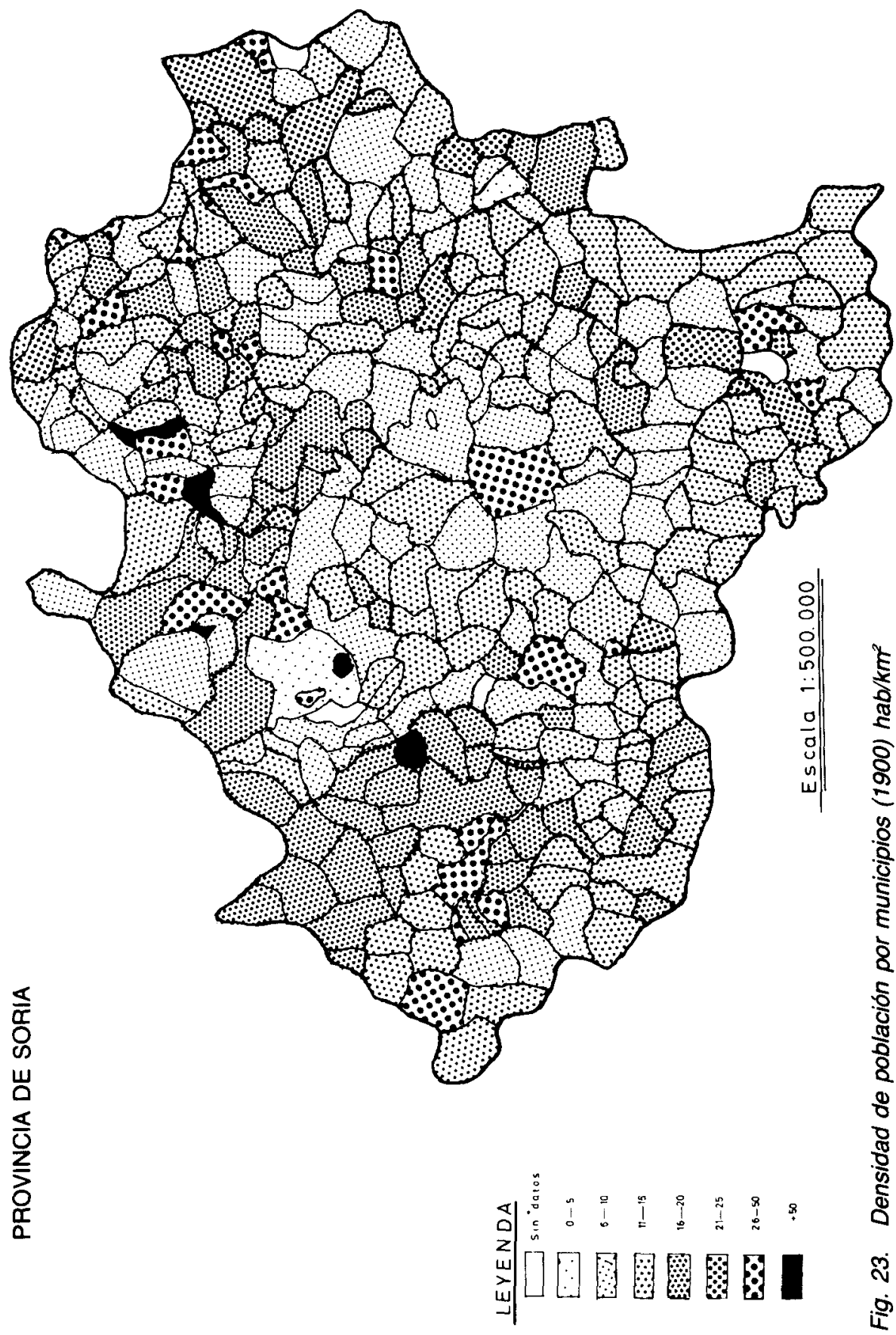


Albacete (16) Ciudad Real $(16,2)$ Cuenca $(14,6)$ Guadalajara $(16,4)$ Huesca $(16,1)$ y Soria $(14,3)$.

En 1965 Soria descendía a 12,44 y Guadalajara a 13,19.

Hemos dejado a propósito sin comentar con el conjunto, el mapa de densidades de 1970 ya que resulta difícil poner en relación las superficies municipales actuales con las del censo anterior después de los cambios experimentados en el último lustro.

En efecto, los 345 municipios de la provincia, han quedado reducidos a 219, tal como estaba previsto en el Plan de Ordenación Provincial. Por ello, para mantener los intervalos de población que teníamos en estudio desde 1900, hemos agrupado las superficies municipales y la población que los integraba, en cada uno de los núcleos importantes que los han absorbido, de tal forma que resulten términos comparables, aunque no reales ya que la comparación resultará hipotética y los valores aproximados.

El Burgo de Osma, por ejemplo que contaba con una superficie de $54,61 \mathrm{~km}$ en 1965, ha pasado a alcanzar en 1970, nada menos que $200,51 \mathrm{~km}$ con los siete términos agrupados. Por eso, deberemos sumar la población de 1965 que integraba estos términos anexionados recientemente, con el fin de averiguar si la densidad de población correspondiente a ese territorio ha aumentado o disminuido con respecto a la actual.

Debe de quedar claro que nos referimos tanto en los mapas de densidad como en los de aumento y disminución de la población, a superficies municipales modificadas y no a términos en sí, de tal forma que es posible que un municipio siguiese una línea de evolución progresiva y al aumentar la extensión del término, sin aportaciones positivas de población de como resultado una densidad baja, progresiva y a la inversa.

¿Que criterios se han seguido en la agrupación de estos municipios?

A simple vista, han sido los de la línea del Duero y los lindantes a los límites provinciales los que han absorbido la mayor parte. Se trata en muchos de los casos, de municipios que en 1970 eran mercado principal de entidades más pequeñas por razones de proximidad o importancia de los servicios.

Así Berlanga de Duero, a $34 \mathrm{~km}$ de Almazán, junto al río Escalote afluente del Duero que forma el vértice del triángulo Burgo de Osma, Berlanga de Duero y Almazán la fusión de ocho municipios hasta el límite provincial con Guadalajara entre los Altos de Barahona y el extremo 
Variables demográficas en una provincia española: El caso de Soria

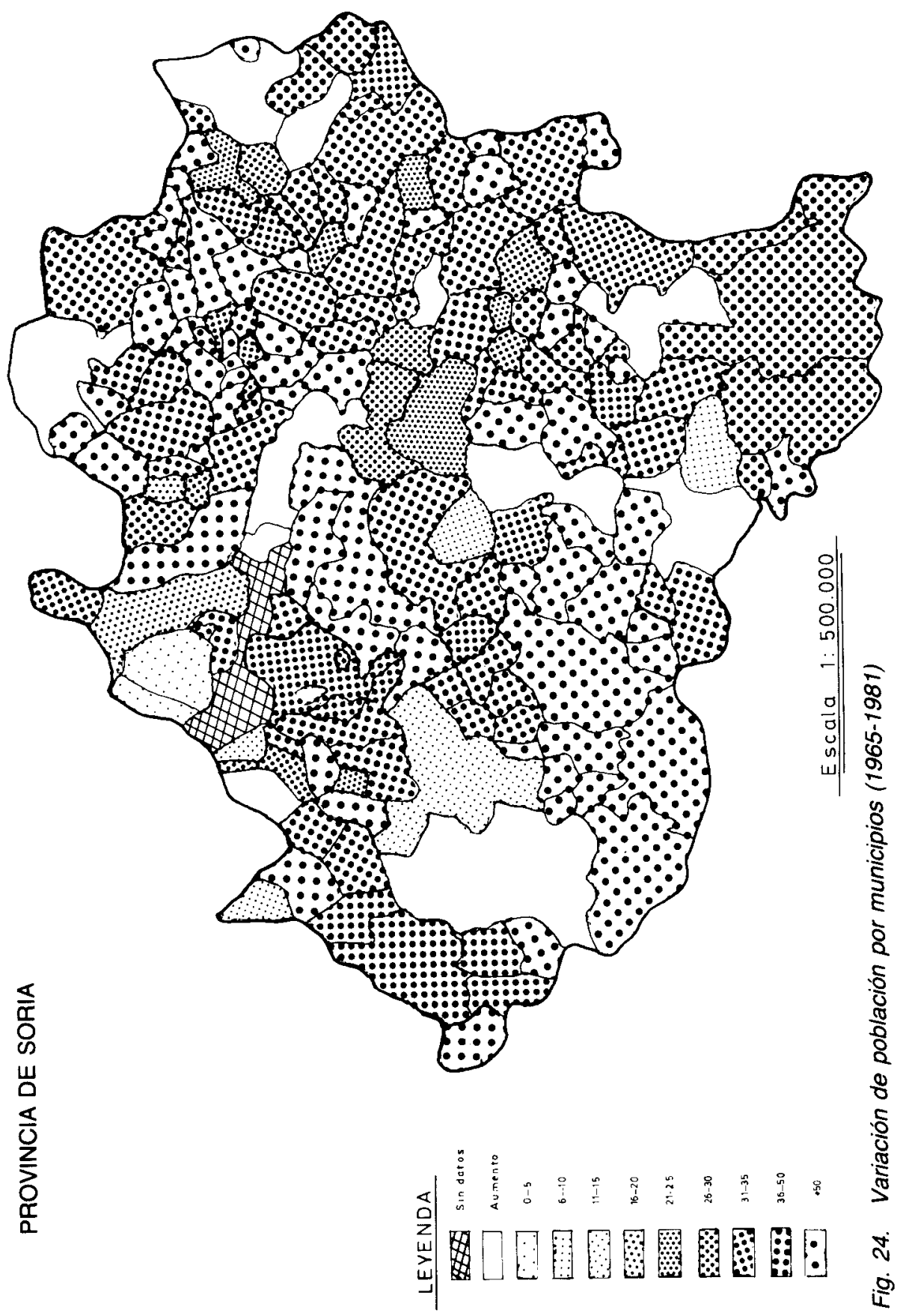


oriental de la Sierra de Pela. Estas anexiones le han supuesto un aumento real de población de hecho que ha pasado de 1.572 habitantes en 1965 a 2.243 en 1970; ahora bien, considerando que la población que ocupaba el territorio unificado, recientemente, era en 1965 de 2.698 habitantes, resulte una disminución real de 465 habitantes y una densidad bajísima de 10,18 más de la mitad con respecto a la de 1965: 27,01.

Caso distinto supone el Burgo de Osma, en plena altiplanicie soriana, a orillas del río Ucero, asentado en el eje que forma de N-S con el Caracena, que ofrece un aumento de 303 habitantes respecto los que habitaban el mismo término en 1965, dando sin embargo una densidad actual de 20,33, notablemente más baja que la de 55,20 de 1965. Y lo mismo podiamos decir de San Esteban de Gormaz, Langa de Duero y Almarza por citar los más representativos.

A lo largo del eje Duero-Tera y de S-N, en la ruta de la carretera de Logroño, tres municipios que han englobado un total de 15 entidades Garray, Golmayo y Los Rábanos forman un cinturón de descongestión en torno a Soria capital, siguiendo un descenso importante, caracteristica general de la provincia que se aprecia de forma alarmante en el mapa de densidad de 1970.

Existe un dominio casi absoluto de las gamas correspondientes a los dos primeros intervalos $0-5$ y 6-10 que cubren prácticamente todo el mapa.

La zona Norte cuenta con la mayor proporción de municipios menores de 100 habitantes, y aunque la densidad demográfica de la subzona de Pinares es algo superior a la media provincial, la del conjunto de la zona Norte resulta inferior, debido a la influencia del valle de Tera y $S$. Pedro Manrique.

Olvega, Fuentes de Magaña, Almajano, Duruelo de la Sierra, Vinuesa, San Leonardo y Navaleno, constituyen los núcleos más importantes de población después de la capital. Corresponden al $6 .^{\circ}$ intervalo (26-50) y son prácticamente los únicos que no han sufrido cambios y permanecen del 65 al 70 con una densidad de población estable.

La zona central es la más extensa y con mayor número de municipios, por tanto, la más afectada con las nuevas anexiones; solamente Soria y Almazán mantienen su densidad y se pueden considerar municipios progresivos.

Arcos de Jalón, el Burgo de Osma y San Esteban de Gormáz, presentan una densidad sensiblemente inferior a la de 1965, como consecuencia de los cambios sufridos en su territorio. 
No obstante la densidad demográfica es algo superior a la media provincial ya que se cuenta con la capital y con estos municipios importantes que hemos citado.

Esta zona central fue la más progresiva durante la primera mitad de siglo, con tasa anual media de crecimiento de $0,26 \%$ que la clasifica como de carácter estacionario, pero a partir de 1960 , al igual que las demás zonas, se vuelve claramente regresiva con tasa del $-0,73 \%$ y únicamente la capital aumenta, debido principalmente a la migración interprovincial.

En cuanto al aumento y disminución de la población, se observa el predominio casi absoluto de la debilidad de población, acelerándose la disminución de manera progresiva en el período reciente del 60-70.

Los signos de aumento son pocos y aislados y están en un grado, que queda muy por debajo del aumento medio de la nación en conjunto.

Los porcentajes más altos de aumento localizados en la línea del Duero, Tierra de Agreda y Valle del Jalón. La atracción hacia las zonas de mejores recursos económicos, queda una vez más puesta de manifiesto ahora.

La zona progresiva, coincide en general con las grandes explotaciones madereras de la provincia; la despoblación del páramo en beneficio del valle es evidente, ya que acusa el mayor porcentaje de disminución al igual que la zona intermedia del sur de pinares.

En el mapa de 1981, se mantiene la misma tónica, es decir amplias zonas con densidades muy bajas, que no llegan a $10 \mathrm{~h} / \mathrm{km}^{2}$. La evolución ha sido el que algunos municipios hayan perdido población y por tanto densidad, siendo los menos, y de forma puntual los que la han elevado.

La distribución de la población en la provincia de Soria.

Podemos afirmar, que en toda la provincia predomina casi de forma absoluta el hábitat concentrado, tanto el que se refiere a las capitales de los municipios como el que vive en entidades. Hay que hacer constar que estas entidades, no son en la mayoría de los casos, más que formas más pequeñas de concentración, siendo realmente el número de habitantes que viven en dispersión, muy reducido.

Burgo de Osma, Berlanga de Duero, Almazán y San Esteban de Gormaz son claros ejemplos de núcleo de población compacta, que agru- 


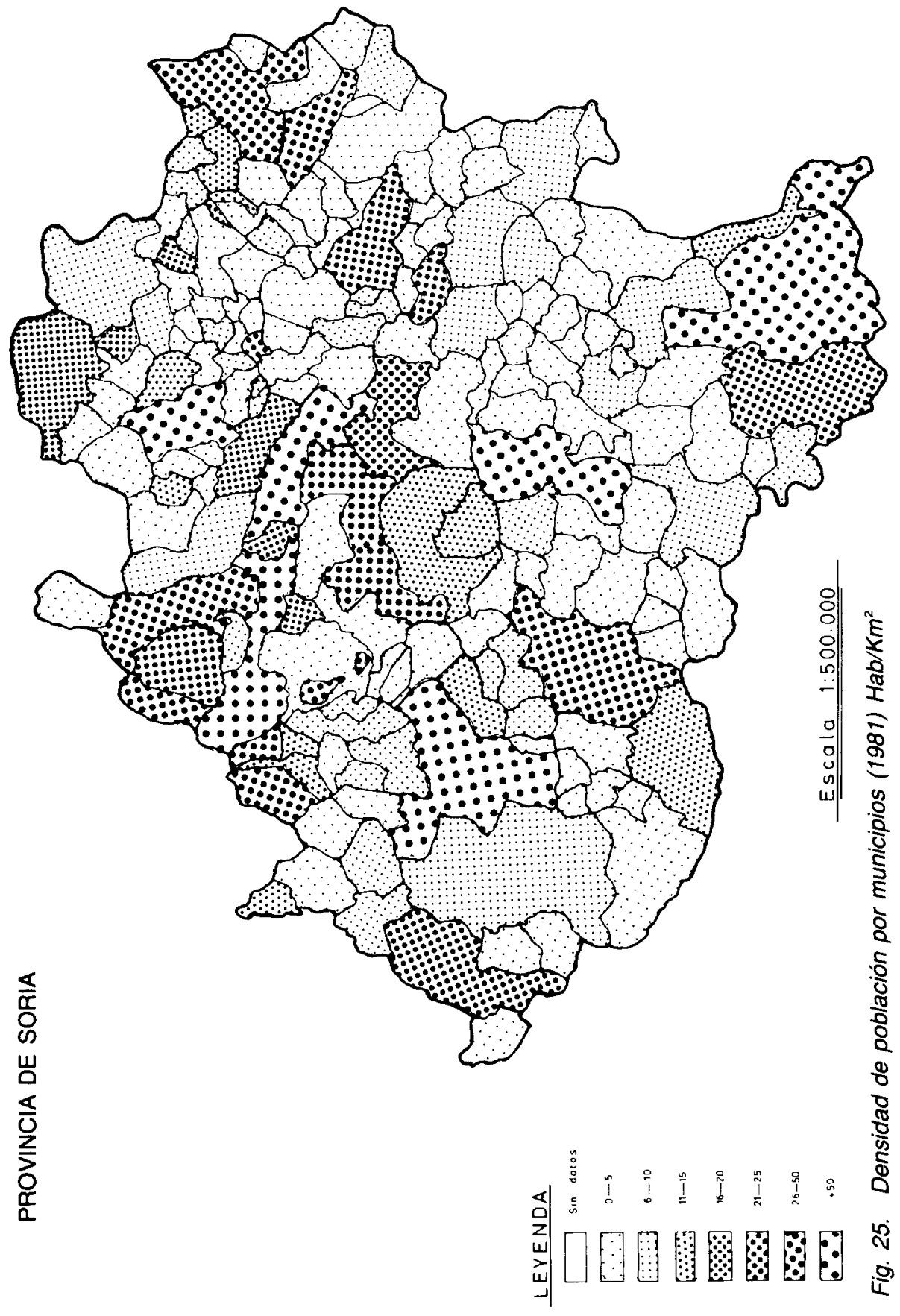


pan bajo su zona de influencia pequeños minicipios, dedicados principalmente a una agricultura cerealista.

En las serranias meridionales de formación triásica y miócena, se dan las tierras más pobres de la provincia. Los escasos rendimientos de la tierra que abunda en yermos y eriales, y la dureza del clima, determinan la escasez de población y la emigración sistemática; abundan aquí los núcleos pequeños de población dedicados a una economia de subsistencia, agrícola-ganadera, pobre y atrasada.

El NW lluvias abundantes, dominio aún del cretácico, alimenta la zona de pinares rica por la explotación de sus bosques, que se traduce en una importante fuente de ingresos para la provincia. Los núcleos de población son en esta zona poco numerosos, pero grandes con elevada densidad y distantes unos de otros.

La zona del NE de terrenos margosos, de difícil cultivo agrícola por la dureza del clima, es típicamente ganadera, con grandes extensiones de astizales de verano de hierbas y matas, que alimentan ganado ovino y porcino, base de su economia.

$Y$ finalmente, en el Piedemonte, formado por conglomerados y molasas del terciario, se asienta Soria, la capital, que abarca la transición de la zona montañosa, forestal y ganadera y el valle de economía cerealista.

La superficie provincial ha experimentado notables cambios desde el censo del 60 en cuanto a delimitación de términos municipales se refiere. Hasta ahora, Soria era el caso típico de provincia con población minimizada, compuesta por un número considerable de pequeños núcleos rurales distribuidos de forma bastante uniforme, lo que hacia que 10.301 $\mathrm{km}^{2}$ estuviesen fragmentados en 345 términos municipales con un total de 850 entidades de población; una entidad por cada $15 \mathrm{~km}$ y un municipio por cada $30 \mathrm{~km}$.

En la actualidad, el número de municipios ha quedado reducido a 219 y los términos han ampliado considerablemente sus límites, pero la distribución de la población sigue siendo prácticamente la misma. Se concentra con mayor intensidad en el NE la sierra, Tierra de San Pedro Manrique, dominio de los pequeños núcleos rurales. En el $\mathrm{N}$ la concentración es menor, ya que coincide con las zonas húmedas de pinares comunitarios con núcleos aislados de población.

En general la dispersión es bastante rara en la provincia. Solo en torno a Soria, Almazán, Burgo de Osma, y en menor escala a orillas del Duero y Jalón, encontramos granjas o alquerías en número escaso. 


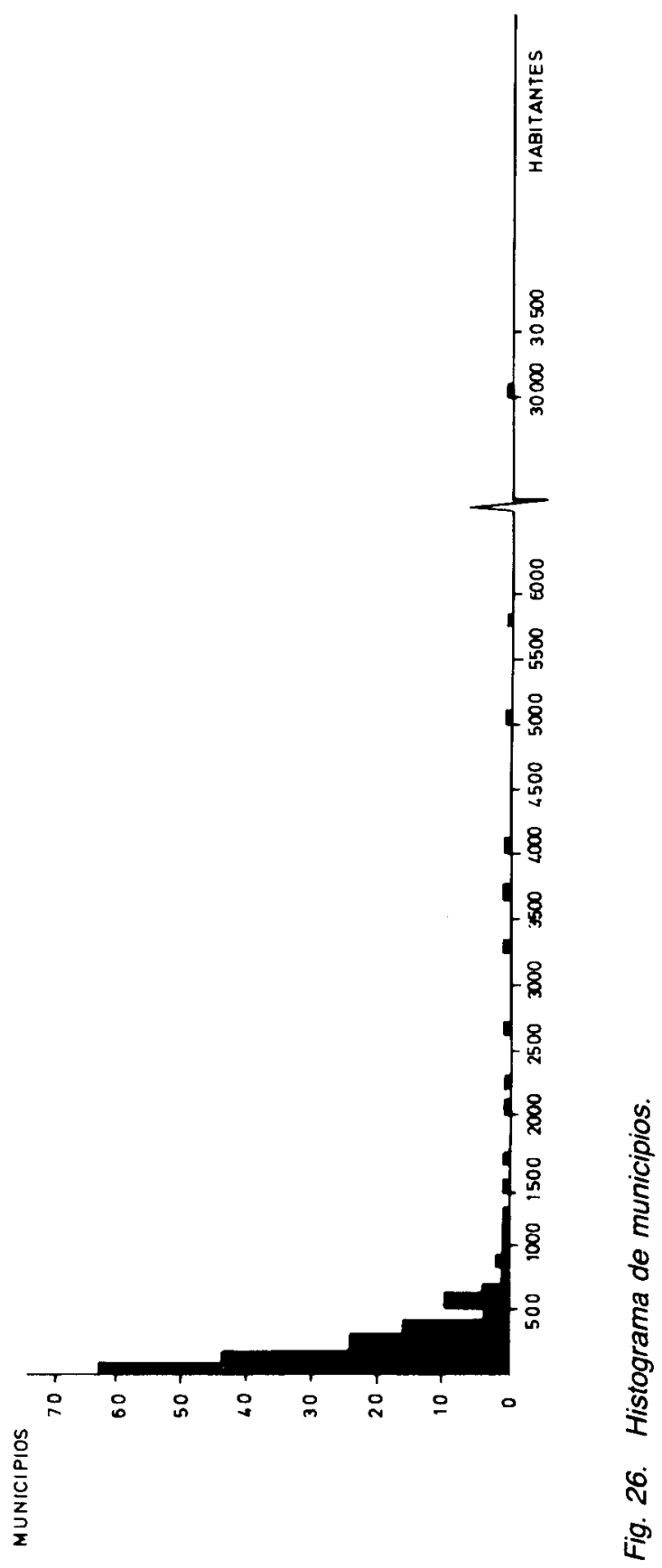


Domina pues la población concentrada. Por muy pequeño que sea un pueblo, existe una natural tendencia a apiñarse en núcleos compactos. Estas agrupaciones obedecen a varios factores: causas físicas que impusieron la vida en común para desarrollar una actividad favorable en un medio hostil, o razones históricas que impusieron la concentración.

Para estudiar la evolución de la población soriana lo más expresivamente posible, vamos a partir de principios de siglo, 1900, saltando a continuación a 1950, para una vez observados los cambios en la primera mitad de siglo, establecer comparación con los censos más inmediatos, $1960,1965,1970$ y 1981.

Para ello, atendiendo al número de habitantes de cada uno de los municipios, los clasificaremos teniendo en cuenta los siguientes intervalos:

\section{NÚCLEO DE MUNICIPIOS EN:}

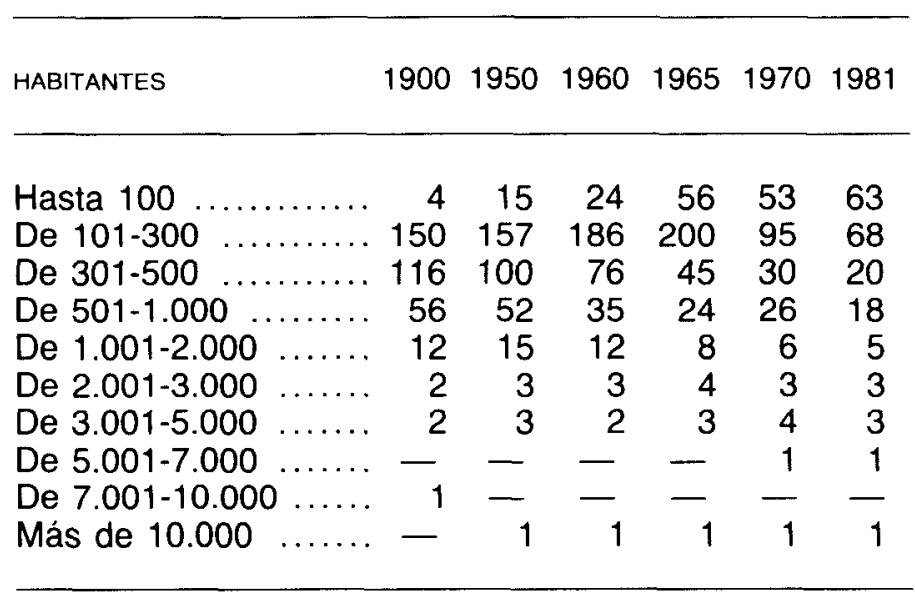

Comparando los dos primeros años, observamos que apenas existe variación notable. En los intervalos de menos población correspondientes al $1 .^{\circ}$ y $2 .^{\circ}$ grado, se aprecia un aumento de municipios. Corresponde a los núcleos de población que alcanzan los 100 habitantes y no sobrepasan los 300 .

Un aumento del número de municipios, se observa igualmente en los de mayor número de habitantes, a partir de mil, correspondientes al $5 .^{\circ}$ grado de los intervalos que proponemos, hasta el $6 .^{\circ}$ y $7 .^{\circ}$ que alcanzan los 5.000 habitantes. 
Son pues los extremos los que aumentan, en contraposición a los municipios de 300 a 500 y de 500 a 1.000 habitantes, cuyo número disminuye de 1900 a 1950 .

En los años sesenta y sesenta y cinco apreciamos un aumento del número de municipios de menos población, que corresponden a los grados $1 .^{\circ}$ y $2 .^{\circ}$ de los intervalos propuestos, y a partir de aquí, la tónica general es de rápido descenso excepto en el $8 .^{\circ}, 9 .^{\circ}$ y $10 .^{\circ}$ que se mantiene invariable desde 1950 por corresponder exclusivamente a Soria capital, única ciudad que sobrepasa los 10.000 habitantes, no existen núcleos de población superior a los 6.000 habitantes y se pasa entonces del 7. ${ }^{\circ}$ al $10 .^{\circ}$ grado bruscamente, sin ninguna graduación.

Comparando globalmente los años mencionados, 1900, 1950, 1960 y 1965 , se observa claramente un aumento considerable y progresivo del número de municipios pertenecientes a los primeros grados de la clasificación; aumento que se interrumpe a partir del $3 .^{\circ}$ grado, y que apenas sufre variación en los últimos, que corresponden a los municipios de: Agreda, Almazán, Burgo de Osma y Soria.

Comentario aparte merece 1970. La supresión de 126 municipios respecto al total del censo anterior, unido al proceso de despoblación de la provincia acelerado en los últimos diez años, hace que el cuadro presente variaciones importantes en los primeros intervalos, que corresponden en censos anteriores, a pequeños municipios desaparecidos en la actualidad, o englobados en otros mayores. Los intervalos $3 .^{\circ}, 6{ }^{\circ}$ y $7 .^{\circ}$ permanecen prácticamente con los mismos valores. Tan solo el Burgo de Osma, con 5.000 habitantes se destaca como ciudad importante despues de la capital.

El histograma realizado con los datos de 1981, resalta frente a otros años la disminución del tamaño de los municipios a pesar de las concentraciones de las entidades de población de menor tamaño. Solo han aumentado los municipios menores de 100 habitantes, el resto han sufrido pérdidas importantes.

Este histograma se puede estudiar mejor con los datos del incremento de población entre 1970-1981, donde las poblaciones que se mantienen son aquellas de más de 1.000 habitantes que son las que comportan el intento de mantener la población en la provincia. 


\section{BIBLIOGRAFIA}

ANES, G. (1974): "Las crisis agrarias en la España moderna», Taurus, Madrid.

Arbelo, A. (1962): "Las dos fases de la natalidad en Europa", Rev. Internacional de Sociología. Año XXIV, núm. 95-96. C.S.I.C. Inst. ${ }^{\circ}$ Balmes. Madrid.

Carande, R. (1965): “Carlos V y sus banqueros I. La vida económica en Castilla (1515-1565): 2. ${ }^{a}$ Edic., Sociedad de Estudios y Publicaciones 1949-1967. Madrid.

Dominguez Ortiz, A. (1963): «La sociedad española en el siglo XVII», T.I., Editora Nacional, Madrid.

KIEIN, J.: “The Mesta” 1273-1836.

NADAL, J. (1976): “La población española». (Siglos XVI a XX). Ariel. Barcelona (Espluges de Llobregat).

Ruiz Martín, F. (1967): "La población española al comienzo de los tiempos modernos", Cuadernos de Historia, núm. 1 (Anejo de la Rev. Hispania), pág. 198 y siguientes.

SÁNCHEZ LOPEZ, F. (1969): “Emigración Española a Europa». Madrid. Confederación Española de Cajas de Ahorro.

VICENS ViVES, A. (1972): «Historia social y económica de España», t. IV. Barcelona, Edit. Teide, pág. 321. 